\title{
How do epidemics induce behavioral changes?
}

R. Boucekkine, R. Desbordes and H. Latzer

Discussion Paper 2008-25

\section{Département des Sciences Économiques de l'Université catholique de Louvain}




\title{
CORE DISCUSSION PAPER
}

$2008 / 42$

\section{How do epidemics induce behavioral changes? \\ Raouf BOUCEKKINE ${ }^{1}$, Rodolphe DESBORDES ${ }^{2}$ and Hélène LATZER ${ }^{3}$}

July 2008

\begin{abstract}
This paper develops a theory of optimal fertility behavior under mortality shocks. In a 3periods OLG model, young adults determine their optimal fertility, labor supply and life-cycle consumption with both exogenous child and adult mortality risks. For fixed prices (real wages and interest rate), it is shown that both child and adult one-period mortality shocks raise fertility due to insurance and life-cycle mechanisms respectively. In general equilibrium, adult mortality shocks give rise to price effects (notably through rising wages) lowering fertility, in contrast to child mortality shocks. We complement our theory with an empirical analysis on a sample of 39 Sub-Saharan African countries over the 1980-2004 period, checking for the overall effects of the adult and child mortality channels on optimal fertility behavior. We find child mortality to exert a robust, positive impact on fertility, whereas the reverse is true for adult mortality. We further find this negative effect on fertility of a rise in adult mortality to dominate in the long-term the positive effect on demand for children resulting from an increase in child mortality.
\end{abstract}

Keywords: fertility, mortality, epidemics, HIV

JEL Classification: J13, J22, O41

\footnotetext{
${ }^{1}$ CORE and IRES, Université catholique de Louvain, Belgium and University of Glasgow. E-mail: raouf.boucekkine@uclouvain.be. This author is also member of ECORE, the newly created association between CORE and ECARES.

2 University of Strathclyde, U.K. E-mail: rodolphe.desbordes@strath.ac.uk

${ }^{3}$ IRES, Université catholique de Louvain, Belgium. E-mail: helene.latzer@uclouvain.be
}

We are grateful to two anonymous referees for numerous suggestions which have decisively shaped this version. We acknowledge the financial support of the Belgian research programmes PAI P5/10 and ARC 03/08-302. The usual disclaimer applies.

This paper presents research results of the Belgian Program on Interuniversity Poles of Attraction initiated by the Belgian State, Prime Minister's Office, Science Policy Programming. The scientific responsibility is assumed by the authors. 



\section{Introduction}

Recently, a controversy has been taking place around the fertility impact of the HIV/AIDS epidemic. While the study of Young (2005) concerning the South-African case has concluded that the epidemic leads to a decrease in fertility, Kalemli-Ozcan (2008a) has identified the opposite effect on a panel of African countries over the 1985-2004 period. At the heart of both Young (2005) and Kalemli-Ozcan (2008a)'s arguments lies the existence of behavioral responses to the epidemics going beyond the simple sexual behavior adjustment to this sexually-transmitted disease. ${ }^{1}$ In other words, both authors claim households will purposefully adapt their fertility choices. Indeed, Kalemli-Ozcan (2008a)'s empirical analysis concludes in favor of a positive effect on fertility of HIV/AIDS despite the negative impacts of the biological and sexual responses to the epidemics, ${ }^{2}$ while Young (2005), using microdata of Sub-Saharan African countries, finds that higher HIV prevalence leads to an increased use of all forms of contraception, confirming that the behavioral changes induced by the epidemics go beyond a simple willingness to reduce unprotected sexual activity.

Young (2005) explains this change in individual behaviors by a rise in the opportunity cost of rearing children, driving down the fertility decisions of women. At the heart of his argument lies the idea that, similarly to what occurred during the Black Death in the fourteenth century, the heavy labor shortage induced by epidemics of the type of HIV/AIDS essentially killing active adults should have a significant positive effect on wages, which might well raise female participation in the labor market and ultimately lead to a lower fertility. Set in more theoretical terms in line with Kremer and Chen (2002), it might be the case that the substitution effect induced by higher wages (lowering fertility through the rising opportunity cost of rearing children) ends up dominating the income effect (increasing fertility through a higher amount of resources available to bring up children). On the other hand, Kalemli-Ozcan (2008a) relates the fertility response to both a shock on adult longevity ${ }^{3}$ and to the survival probability of the children. As far as child mortality is concerned, her argument is tightly linked to the "insurance effect" (Kalemli-Ozcan, 2002), deriving from an increasing uncertainty about children's survival to the adult age: the perception of a rise in child mortality may hence generate a further rationale for increasing the number of offsprings. The ongoing AIDS-fertility debate hence seems to oppose two effects at work in the case of an epidemic shock: on one side the direct, positive impacts on fertility described by Kalemli-Ozcan (2008a) of a diminishing adult survival rate (adult mortality shock) and a decreasing survival probability of children (child mortality shock), and on the other side the indirect, negative "wage effect" on fertility put forward by Young (2005), sort of "secondround" response to the initial adult mortality shock.

\footnotetext{
${ }^{1}$ Kalemli-Ozcan (2008a) provides an overview of the medical literature and concludes that uninfected people, or people believing not to be infected, do not modify their fertility-related behaviors: indeed, in the African case, numerous social and political circumstances are particularly unfavorable to awareness of HIV/AIDS (World Bank, 1997). In particular, Oster (2005), using DHS data on sexual behavior from a subset of African countries, finds that sexual behavior has only been slightly modified since the appearance of the epidemic.

${ }^{2} \mathrm{As}$ far as the biological changes are concerned, the fertility of HIV-positive women has been found to be about 30\% lower than HIV-negative women in SSA, causing a population-attributable decline in total fertility of $0.37 \%$ for every percentage point of HIV prevalence (Lewis et al., 2004). This negative impact on fertility is usually explained by lower coital frequency due to ill health and epidemiological synergies between HIV and other sexually-transmitted infections, which reduce the ability to conceive and increase the risk of foetal loss (Gray et al., 1998).

${ }^{3}$ However, even though she also acknowledges the role of adult mortality shocks as in Young (2005), she argues against the latter that they have a positive effect on fertility decisions, resulting from a quantity/quality trade-off operated by adults once their life span is reduced: they end up investing less in their own education and having more children (Soares, 2005).
} 
We argue along with Young (2005) that the fertility impact of epidemics cannot be finely apprehended by only considering decreasing survival rates, whether it be for adults or children: as far as one is concerned with fertility choices under epidemics, the price effects (and essentially the wage effect) should be accurately isolated. The aim of this paper is to capture those two different types of effects on fertility response to an epidemic shock (the direct mortality effects and the indirect price effects) in a comprehensive, intertemporal general equilibrium framework that will allow us to both precisely decompose the different channels at work and analyze the existing interactions between them. In other words, we aim at studying the influence of mortality shocks in a general equilibrium framework allowing for price effects to arise.

We shall proceed in two steps. We first present an overlapping generations model depicting the individual behavior modifications in response to an epidemic shock. In order to clearly identify the different channels at work in the case of an epidemic shock and their consequences on fertility behavior, we proceed progressively. We first place ourselves in a partial equilibrium framework, where prices (basically the real wage and the interest rate) are given. In this partial equilibrium analysis, we first characterize the optimal fertility, labor supply and saving under transitory mortality shocks. It is of utmost importance to notice that our model encompasses and clearly differentiates the two possible mortality channels in the case of an epidemic such as the one of HIV/AIDS, i.e. first a decrease in the life span (adult mortality shock) and second a lower probability of child survival (child mortality shock). We show that the two types of mortality shocks induce an increase in fertility and a lower labor supply, but that the underlying mechanisms are radically different: while the lower survival probability of children triggers an insurance effect à la Kalemli-Ozcan (2008b), the shock on adult mortality induces a "life-cycle effect" where the reduction in chances to reach senior age decreases the need for life-cycle consumption and increases the desired number of offsprings. We then study how the optimal fertility and labor supply behaviors are modified when we allow for the prices (wages and interest rates) to exogenously move: this part can be considered as an intermediary step towards our final, general equilibrium analysis where those prices will endogenously adapt. We particularly show that under certain parametric conditions, the increase in wages resulting from labor shortage can end up reducing fertility and raising labor supply. Hence, we show that a consequence from the initial adult mortality shock (i.e. the resulting upward adjustment in wages) might end up having opposite effects on the fertility behavior. We then finally take the analysis a step further by closing the model, studying a general equilibrium version where prices (wages and interest rates) are endogenously determined: we then show that child mortality shocks do not have any impact on prices in general equilibrium, and hence unambiguously lead to a rise in fertility. On the other hand, we exemplify the existence of a price effect in the case of a shock on adult mortality, since the latter is found to cause wages to go up: therefore, our model clearly demonstrates that a rise in adult mortality has an ambiguous effect on fertility in a general equilibrium setting. We deem this opposition between the child and adult mortality general equilibrium effects to be the key result of our theoretical model.

In a second step, acknowledging the difficulty to provide a simple and elegant analytical characterization of the cases where the wage effect dominates the mortality effects, we complement our theoretical model with an empirical contribution to the AIDS-fertility debate. We conduct an empirical analysis on a sample of 39 SSA countries over the 1980-2004 period, checking for the overall effects of the adult and child mortality channels on optimal fertility behavior. We find child mortality to exert a robust, positive impact on fertility, whereas the reverse is true for adult mortality. Hence, to interpret those results in the line of our model, it seems that in the case of the HIV/AIDS epidemic in Sub-Saharan countries, the indirect wage effect outweighs the 
direct "life-cycle effect" in the case of an adult mortality shock. We further find this negative effect on fertility of a rise in adult mortality to dominate in the long-term the positive effect on demand for children resulting from an increase in infant mortality. Even though these results tend to support the findings of Young (2005, 2007), it must nevertheless be emphasized that we also show they do not contradict the argumentation of Kalemli-Ozcan (2008a) concerning the effects of child mortality, since an increase in precautionary demand for children following a shock on child mortality is also exemplified by our empirical results. However, we find this effect to be eventually outweighed by the full impact of a rise in HIV prevalence on adult mortality.

To summarize, the original contributions of this paper are twofold. We first provide a comprehensive intertemporal, general equilibrium framework for the study of epidemics, encompassing not only the direct effects of mortality shocks (both child and adult) but also the "second-round" effects occurring once you allow for endogenously determined equilibrium prices. We are hence able to exemplify the opposite general equilibrium effects of child and adult mortality shocks: while the first one is found to exert an unambiguously positive effect on fertility through the absence of price effect, the effect on fertility of the second one is ambiguous. Beyond that novel contribution to the literature on life expectancy and growth ${ }^{4}$, we believe this paper then also sheds light on the particular ongoing debate between Kalemli-Ozcan (2008a) and Young (2005) in the HIV/AIDS case. First, our theoretical part provides a sort of synthesis of the 2 contributions, exemplifying the co-existence of all the effects identified by the two papers. Our empirical part then confirms the existence of both an increase in precautionary demand for children following a rise in child mortality and a negative influence on fertility of a rise in adult mortality, which eventually is found to dominate in the long-run.

The paper is organized as follows. Sections 2 and 3 present our theoretical model and its predictions concerning rational behavior under epidemics, first in a partial equilibrium setting with fixed prices (section 2) and then moving to general equilibrium results (section 3). Section 4 presents our empirical exercise and reports the results obtained. Section 5 concludes.

\section{Rational behavior under epidemics: partial equilibrium theory}

In order to clearly identify the different forces at work in the influence of an epidemic shock on the fertility and labor supply behavior, we shall start with a partial equilibrium analysis where prices (basically the real wage and interest rate) are given. Within this simple framework, we first characterize optimal fertility, labor supply and saving behavior under transitory mortality shocks. In a second step, we also study in this partial equilibrium framework how this behavior is altered if additionally the epidemic shocks also exogenously modify prices, especially real wages. We study in particular the influence of the "wage effect", defined as the increase in real wages induced by the heavy shortage in labor supply resulting from massive epidemics like the Black Death or AIDS. This positive effect on wages is not only emphasized by Young (2005) in his inspection of the South African AIDS tragedy, but is also commonly admitted by sociologists and historians (Herlihy, 1997) concerning epidemics such as the Black Death. ${ }^{5}$

\footnotetext{
${ }^{4}$ While a comprehensive theoretical analysis of the relationship between life expectancy, education and fertility has already been provided by Hazan and Zoabi (2006), our model contributes to the literature by tackling the problem of behavioral answer to different types of mortality shocks, and studying in a transparent and tractable way the combined impact of a shorter survival probability and a positive effect on wages.

${ }^{5}$ This positive effect on wages is actually even acknowledged by economy textbooks (Mankiw, 2005).
} 
The model presented here can be seen as a reasonable combination of the Young (2005) static model and Zhang and Zhang (2005) overlapping generations model. It is however important to signal right away that in order to keep this analytical part as algebraically transparent as possible, we don't explicitly allow for the traditional trade-off "quality vs quantity of children" that is present in both mentioned models through the educational choices of the parents. Indeed, for the sake of computational clarity, we here choose to focus on the fertility decision (quantity of children), not including an education variable. One should however notice that adding such a trade-off to our theoretical set-up would deliver the typical outcome that in response to the epidemic shocks, parents move the quality and quantity of children in opposite directions. Hence, implications for optimal education decisions will result quite naturally once we have determined the optimal fertility behavior.

Last but not least, it should be noted that we depart from the previous models by including exogenous child mortality, which is a crucial part of our story. This modeling aspect has been treated in the spirit of Kalemli-Ozcan (2008b), with a child mortality shock occurring at the beginning of the period and hence a rearing effort being made only in the case of surviving children.

\section{$2.1 \quad$ The model}

The model is a 3 periods, one good overlapping generations model. An individual born in period $t$ has a probability $q_{t}$ to survive to the young adult age in period $t+1$, and conditionally to this survival, he can live as a senior adult in period $t+2$ with probability $p_{t+1}$. In the first period of life (childhood), the individual spends all his time endowment (say one unit of time) having leisure. In period $t+1$, he becomes a young adult with (exogenous) probability $q_{t}$. A surviving young adult consumes $c_{t+1}$, has $n_{t+1}$ children, works a proportion $l_{t+1}$ of his unit time endowment, paid at an exogenous wage per unit of time $w_{t+1}$, and saves $s_{t+1}$ for consumption in his old age (provided he survives to this age). In our simple model, only young adults work, there is no child labor, and we also disregard social security mechanisms. As usual, having children is costly: in our model, raising children costs a certain amount of the overall time endowment. We assume, in the spirit of Kalemli-Ozcan (2008b), that child mortality occurs at the beginning of the period, and is observed by parents before they decide about their rearing effort. ${ }^{6}$ The rearing effort is therefore assumed to depend only on surviving children. ${ }^{7}$ To simplify, we model this cost as a proportion $\theta q_{t+1} n_{t+1}$ of time endowed, with $\theta>0$. The young adult then becomes a senior adult with probability $p_{t+1}$. A senior adult consumes $c_{t+2}$ out of the savings made in $t+1$. A classic feature in this kind of framework is then to assume the existence of an annuity market which guarantees that survivors get the savings plus interests of the young adults who die before reaching the seniority. Accordingly, the return rate to savings is given by $\frac{R_{t+2}}{p_{t+1}}$.

As already signaled and justified, with respect to Zhang and Zhang (2005), one can notice

\footnotetext{
${ }^{6}$ In Kalemli-Ozcan (2008b), it should be noted that both fertility and education decisions are modeled, with parents operating fertility choices before the uncertainty is realized, as opposed to investing only in the human capital of surviving children (education choice). As it has already been signalled, our model however does not explicitly allow for educational choices, and we hence consider rearing costs in their broadest acception of the overall time parents have to dedicate to a child if this one survives. Hence, we model the rearing effort decision as being similar in its timing to the education effort decision in Kalemli-Ozcan (2008b).

${ }^{7}$ One can consider the alternative assumption of parents deciding about their rearing effort before the uncertainty is realized. This case is studied in Kalemli-Ozcan (2003), where both the fertility and education optimal choices are made simultaneously under uncertainty about the number of surviving children. In our set-up, it would however change markedly the algebra and complicate the technical discussion without changing the main sensitive point of the paper on the contrasting behavioral impacts of adult Vs child mortality.
} 
that we omit schooling and human capital accumulation. Indeed, introducing them would result in a system of 7 equations as opposed to 5 below: the economic gains from such an extension are completely overshadowed by the algebraic cost. Instead we choose to stick to a simpler model, that will guarantee a precise identification of the effects at work concerning the fertility and labor supply decisions under epidemic shocks. A more fundamental difference that we will comment now comes from preferences, whose specification is closer to the spirit of Beckerian behavioral models such as the one developed by Young (2005). Indeed, we assume that the preferences of a (surviving) young adult individual born in $t$ are given by:

$U\left(c_{t+1}, n_{t+1}, l_{t+1}, c_{t+2}\right)=\frac{c_{t+1}^{1-\sigma_{c}}}{1-\sigma_{c}}+\alpha_{1} \frac{\left(q_{t+1} n_{t+1}\right)^{1-\sigma_{n}}}{1-\sigma_{n}}+\alpha_{2} \frac{\left(1-\theta q_{t+1} n_{t+1}-l_{t+1}\right)^{1-\sigma_{l}}}{1-\sigma_{l}}+p_{t+1} \alpha_{3} \frac{c_{t+2}^{1-\sigma_{c}}}{1-\sigma_{c}}$

where $\alpha_{i}, i=1,2,3$, are strictly positive constants, and $\sigma_{c}, \sigma_{n}$ and $\sigma_{l}$, are the usual positive elasticity parameters respectively related to consumption (either "young" or "old" consumption), number of children and leisure. ${ }^{8}$

Hence, consistently with Young's static preferences, and since labor supply response to epidemic shocks is a fundamental aspect of our paper, we introduce disutility of working (and rearing children) in the second period of life: young adults enjoy leisure, and working and rearing children reduces their utility. In contrast, Zhang and Zhang (2005) introduce such a leisure term for children, along with their purpose of featuring educational choices. Also notice that utility depends on the number of surviving children, a feature which can be found either in Kalemli-Ozcan (2008b) or in evolutionary biology-based growth models à la Galor and Moav (2002).

Finally, the general iso-elastic specification for utility terms is aimed for generality. As we shall see later, some important behavioral implications of epidemics do depend on the elasticity parameters.

The budgetary constraints for periods $t+1$ and $t+2$ are as follow:

$$
\begin{aligned}
c_{t+1}+s_{t+1} & =w_{t+1} l_{t+1}, \\
c_{t+2} & =\frac{R_{t+2}}{p_{t+1}} s_{t+1},
\end{aligned}
$$

inducing the intertemporal budgetary constraint

$$
c_{t+1}+\frac{p_{t+1}}{R_{t+2}} c_{t+2}=w_{t+1} l_{t+1} .
$$

Optimal behavior is obtained by maximization of the utility function with respect to the four decision variables $\left(c_{t+1}, n_{t+1}, l_{t+1}, c_{t+2}\right)$ under the constraint (3). The resulting optimization problem is as follows. Call $\lambda_{t+1}$ the Lagrange multiplier associated to (3). The first-order

\footnotetext{
${ }^{8}$ Of course, in case one of these elasticity parameters is equal to 1 , the corresponding utility term becomes logarithmic.
} 
conditions with respect to the four variables above in this order are:

$$
\begin{aligned}
c_{t+1}^{-\sigma_{c}} & =\lambda_{t+1}, \\
\theta \alpha_{2} q_{t+1}^{\sigma_{n}}\left(1-\theta q_{t+1} n_{t+1}-l_{t+1}\right)^{-\sigma_{l}} & =\alpha_{1} n_{t+1}^{-\sigma_{n}}, \\
\alpha_{2}\left(1-\theta q_{t+1} n_{t+1}-l_{t+1}\right)^{-\sigma_{l}} & =\lambda_{t+1} w_{t+1}, \\
\alpha_{3} c_{t+2}^{-\sigma_{c}} & =\frac{\lambda_{t+1}}{R_{t+2}} .
\end{aligned}
$$

Characterizing optimal behavior amounts to solving the system (3) to (7) in the five variables $\left(c_{t+1}, n_{t+1}, l_{t+1}, c_{t+2}, \lambda_{t+1}\right)$, all strictly positive, under the time resource constraint, $\theta q_{t+1} n_{t+1}+$ $l_{t+1}<1$, for given prices $w_{t+1}$ and $R_{t+2}$, and given probabilities $q_{t+1}$ and $p_{t+1}$. The first proposition shows that this problem has a unique solution.

Proposition 1 The system (3) to (7) has a unique solution in $\left(c_{t+1}, n_{t+1}, l_{t+1}, c_{t+2}, \lambda_{t+1}\right)$, all strictly positive, satisfying $\theta q_{t+1} n_{t+1}+l_{t+1}<1$.

Proof: Combining (3), (4) and (7), one can find

$$
c_{t+1}=\frac{w_{t+1} l_{t+1}}{1+p_{t+1} \alpha_{3}^{\frac{1}{\sigma_{c}}} R_{t+2}^{\frac{1}{\sigma_{c}}-1}} .
$$

Now, combining (5) and (6), one gets

$$
\alpha_{1} n_{t+1}^{-\sigma_{n}}=\theta q_{t+1}^{\sigma_{n}} \lambda_{t+1} w_{t+1}
$$

which yields by (4) and (8)

$$
\alpha_{1} n_{t+1}^{-\sigma_{n}}=\frac{\theta q_{t+1}^{\sigma_{n}} w_{t+1}^{1-\sigma_{c}}}{\left(1+p_{t+1} \alpha_{3}^{\frac{1}{\sigma_{c}}} R_{t+2}^{\frac{1}{\sigma_{c}}-1}\right)^{-\sigma_{c}}} l_{t+1}^{-\sigma_{c}} .
$$

Now, it is straightforward to see that the proposition is done if we prove that the system (5)-(9) admits a unique solution in $n_{t+1}$ and $l_{t+1}$ satisfying $\theta q_{t+1} n_{t+1}+l_{t+1}<1$. Using (9) to express $l_{t+1}$ as a function of $n_{t+1}$, and substituting this function in (5), we get a single equation in $n_{t+1}$, which is fundamental to our purposes:

$$
\alpha_{1} n_{t+1}^{-\sigma_{n}}=\theta \alpha_{2} q_{t+1}^{\sigma_{n}}\left[1-\theta q_{t+1} n_{t+1}-q_{t+1}^{\frac{\sigma_{n}}{\sigma_{c}}} \Omega_{t+2}^{-\frac{1}{\sigma_{c}}} w_{t+1}^{\frac{1}{\sigma_{c}}-1} n_{t+1}^{\frac{\sigma_{n}}{\sigma_{c}}}\right]^{-\sigma_{l}},
$$

where $\Omega_{t+2}=\frac{\alpha_{1}}{\theta}\left(1+p_{t+1} \alpha_{3}^{\frac{1}{\sigma_{c}}} R_{t+2}^{\frac{1}{\sigma_{c}}-1}\right)^{-\sigma_{c}}$. Denote by $\bar{n}_{t+1}$, the number of children satisfying the equality (implying zero leisure): $\theta q_{t+1} \bar{n}_{t+1}+q_{t+1}^{\frac{\sigma_{n}}{\sigma_{c}}} \Omega_{t+2}^{-\frac{1}{\sigma_{c}}} w_{t+1}^{\frac{1}{\sigma_{c}}-1} \bar{n}_{t+1}^{\frac{\sigma_{n}}{\sigma_{c}}}=1$. On the interval $\left(0 ; \bar{n}_{t+1}\right)$, the left-hand side of (10) is a strictly decreasing function from infinity to $\alpha_{1} \bar{n}_{t+1}^{-\sigma_{n}}$ while the right-hand side is increasing from $\theta \alpha_{2} q_{t+1}^{\sigma_{n}}$ to infinity. Therefore, they should be equal at a single point comprised in the interval $\left(0 ; \bar{n}_{t+1}\right)$. This ends the proof. 
We now study the impact of epidemics on the optimal decisions featured in Proposition 1, i.e. the effects on individual behavior of a drop in the survival probabilities $p_{t+1}$ and $q_{t+1}$ for given prices. Then we analyze how this optimal behavior is altered when the latter prices also (exogenously) move.

\subsection{Optimal behavior under mortality shocks}

We consider an epidemic shock affecting only the generation born in period $t$. More precisely, and consistently with AIDS epidemiology, the epidemic first hits the young adults of this generation, lowering the survival probability $p_{t+1}$, then their children, causing the survival probability $q_{t+1}$ to drop. Considering longer epidemic episodes makes the general equilibrium study analytically intractable as one can see in the next section. In this section, we also assume that the prices $w_{t+1}$ and $R_{t+2}$ are fixed.

Suppose the survival probability $p_{t+1}$ goes down. Then, optimal fertility as given by equation (10) is necessarily altered via the term $\Omega_{t+2}$. The same term will also modify labor supply and then savings, as reflected in the following proposition.

Proposition 2 Under given prices $w_{t+1}$ and $R_{t+2}$, a decrease in the survival probability $p_{t+1}$ always raises fertility $n_{t+1}$ and reduces labor supply $l_{t+1}$ and savings $s_{t+1}$, for any $\sigma_{c}$ positive.

Proof: Let us start with optimal fertility response. Indeed, a change in $p_{t+1}$ does not affect the left hand side of (10), it only affects the right-hand side through the term $\Omega_{t+2}$. Because

$$
\Omega_{t+2}^{-\frac{1}{\sigma_{c}}}=\left(\frac{\alpha_{1}}{\theta}\right)^{-\frac{1}{\sigma_{c}}}\left[1+p_{t+1} \alpha_{3}^{\frac{1}{\sigma_{c}}} R_{t+2}^{\frac{1}{\sigma_{c}}-1}\right]
$$

it follows that a drop in the survival probability $p_{t+1}$ will decrease the right-hand side of equation (10). Because the left-hand side is unaffected, and the right-hand side is increasing in $n_{t+1}$, the equality (10) is re-established if and only if optimal fertility rises.

To get the property relative to labor supply, we can use a similar argument. First obtain the corresponding single equation in $l_{t+1}$ combining (5) and (9):

$$
\frac{\alpha_{1}}{\Omega_{t+2}} w_{t+1}^{1-\sigma_{c}} l_{t+1}^{-\sigma_{c}}=\theta \alpha_{2}\left[1-\theta \Omega_{t+2}^{\frac{1}{\sigma_{n}}} w_{t+1}^{\frac{\sigma_{c}-1}{\sigma_{n}}} l_{t+1}^{\frac{\sigma_{c}}{\sigma_{n}}}-l_{t+1}\right]^{-\sigma_{l}},
$$

Then apply the same kind of reasoning as just above on (10). Focusing on equation (11), one can see that the left-hand side is shifted downwards when $p_{t+1}$ drops. Since the function in the left-hand side is decreasing in $l_{t+1}$, this means that $l_{t+1}$ has to decrease to re-establish equation (11) for an unchanged right-hand side. However, in contrast to the fertility analysis above, both sides of the equation (11) are altered. Indeed, a drop in $p_{t+1}$ also causes the right-hand side to shift upwards, via the term $\Omega_{t+2}^{\frac{1}{\sigma_{n}}}$, inducing an additional downward move in $l_{t+1}$ since the right-hand side is increasing in this variable.

It remains to depict how savings are altered. Using (1) and (8), one can express savings as:

$$
s_{t+1}=\frac{p_{t+1} \alpha_{3}^{\frac{1}{\sigma_{c}}} R_{t+2}^{\frac{1}{\sigma_{c}}-1}}{1+p_{t+1} \alpha_{3}^{\frac{1}{\sigma_{c}}} R_{t+2}^{\frac{1}{\sigma_{c}}-1}} w_{t+1} l_{t+1} .
$$

It follows that savings drop when the survival probability goes down for two reasons. On one hand, as demonstrated above, labor supply diminishes following a drop in the adult survival 
probability, triggering a decrease in the overall available resources. On the other hand, $p_{t+1}$ has a direct effect on savings via the term $\frac{p_{t+1} \alpha_{3}^{\frac{1}{\sigma_{c}}} R_{t+2}^{\frac{1}{\sigma_{c}}-1}}{1+p_{t+1} \alpha_{3}^{\frac{1}{\sigma_{c}}} R_{t+2}^{\frac{1}{\sigma_{c}}-1}}$, which is an increasing function of $p_{t+1}$ for a given interest rate. This direct effect simply features that since young adults only save to consume in their senior age, a diminishing probability of survival should lower the incentives to save. Hence, savings unambiguously decrease.

Our results complement those of Zhang and Zhang (2005) to a certain extent. ${ }^{9}$ Indeed, even though their model is built in a general equilibrium framework, preferences are logarithmic, which has the consequence of neutralizing the general equilibrium effects that might arise through an impact on equilibrium prices, as we shall neatly show in the next section. In such a case, and in ours since we focus on partial equilibrium results in this section, prices are neutralized, and so we can compare the mechanisms at work. In both papers, the reduction in survival probability diminishes the need for life-cycle consumption with respect to fertility, which in Zhang and Zhang (2005) implies an increase in fertility, a decrease in savings and a drop in labor supply in the absence of disutility of working and rearing children. In our model, the disutility of working and rearing children is present, and the properties still hold, which ultimately shows their robustness.

More importantly, our results point out that fertility does increase under adult mortality shocks just like it has been shown to behave under child mortality shocks by Kalemli-Ozcan (2002, 2008a,b). In our case, it happens because of a clearly identified life-cycle effect, acting through a diminishing need for life-cycle consumption, while an insurance effect seems to play in the case of child mortality. Since we have also incorporated child mortality à la Kalemli-Ozcan (2008b), we shall go a step further and provide a more comprehensive picture of the impact of child mortality on optimal behavior in our model. The results are reflected in the following proposition.

Proposition 3 Under given prices $w_{t+1}$ and $R_{t+2}$, a decrease in the survival probability $q_{t+1}$ always raises fertility $n_{t+1}$ but leaves labor supply $l_{t+1}$ and savings $s_{t+1}$ unchanged for any $\sigma_{c}$ positive. Moreover, a decrease in $q_{t+1}$ is exactly compensated by a proportional rise in fertility.

Proof: The proof is very simple. Recall equation (10):

$$
\alpha_{1} n_{t+1}^{-\sigma_{n}}=\theta \alpha_{2} q_{t+1}^{\sigma_{n}}\left[1-\theta q_{t+1} n_{t+1}-q_{t+1}^{\frac{\sigma_{n}}{\sigma_{c}}} \Omega_{t+2}^{-\frac{1}{\sigma_{c}}} w_{t+1}^{\frac{1}{\sigma_{c}}-1} n_{t+1}^{\frac{\sigma_{n}}{\sigma_{c}}}\right]^{-\sigma_{l}}
$$

It is straightforward to see that the previous equation can be rewritten as follows:

$$
\alpha_{1}\left(q_{t+1} n_{t+1}\right)^{-\sigma_{n}}=\theta \alpha_{2}\left[1-\theta q_{t+1} n_{t+1}-\Omega_{t+2}^{-\frac{1}{\sigma_{c}}} w_{t+1}^{\frac{1}{\sigma_{c}}-1}\left(q_{t+1} n_{t+1}\right)^{\frac{\sigma_{n}}{\sigma_{c}}}\right]^{-\sigma_{l}}
$$

It follows that a decrease in child survival probability $q_{t+1}$ is "integrally" compensated by a proportional increase in fertility. Moreover, equations (11) and (12) giving optimal labor supply and savings are independent of child mortality $q_{t+1}$.

Some comments are in order. In our model, child mortality shocks induce a "full" insurance effect boosting fertility, while our specification does not allow them to generate any life-cycle type of mechanism. On the contrary, adult mortality induces a full life-cycle effect (driving labor

\footnotetext{
${ }^{9}$ See their Proposition 3, page 50.
} 
supply and savings down while pushing fertility upward), and no insurance behavior. In this sense, our model is able to generate a canonical picture where each type of mortality plays fully its "natural" role. Of course, this picture is likely to be altered if we depart from some essential assumptions made in our simple model. First of all, if children are allowed to work and to contribute to the (intertemporal) resources of the household and/or if they can support seniors via a social security system, then having children would also obey to intertemporal arbitrages. Second, even if we abstract away from the previous considerations, the picture can be quickly less canonical if we depart from a key assumption already signalled and extensively commented at the beginning of our presentation of the model, that is we assume that parents invest in their children after uncertainty about their survival is resolved This amounts to assuming a specific timing. ${ }^{10}$ If we depart from this assumption, then the picture is much more demanding algebraically speaking, and more importantly, it will be definitively less clear, opening the door to counter-factual behaviour. In particular, if we assume that parents invest in their children before uncertainty is resolved, then the optimal response of fertility to child mortality shocks depends strongly on the value of the elasticity parameter $\sigma_{n}$. However, since the main aim of our model is essentially to study the influence of mortality shocks in a general equilibrium framework allowing for price effects to arise, we prefer to stick to this somewhat simplified and canonical picture, that turns out to be consistent with empirical evidence concerning child mortality impact on fertility, and will allow a much better identification of the main effects at work.

\subsection{Impact of changing prices on optimal behavior}

In this sub-section, before moving to general equilibrium we first study how the optimal behavior depicted above is modified when prices exogenously move. As mentioned in the introduction, the literature on epidemics often outlines the role of wages in the propagation of the initial mortality shocks. Our intertemporal framework further has the virtue of exemplifying the role of another possibly important price, i.e. the interest rate.

First, a quick look at equations (10) and (11) is enough to identify a special case: when the utility term with respect to consumption is logarithmic, that is when $\sigma_{c}=1$, neither the wage $w_{t+1}$ nor the interest rate $R_{t+2}$ matter in fertility and labor supply choices, and the "price effects" are hence no longer active in this case. Indeed, both in equations (10) and (11), all the wage terms disappear once we set $\sigma_{c}=1$. In the case of the interest rate $R_{t+2}$, this result comes from the fact that $R_{t+2}$ essentially operates through the term $\Omega_{t+2}=\frac{\alpha_{1}}{\theta}\left(1+p_{t+1} \alpha_{3}^{\frac{1}{\sigma_{c}}} R_{t+2}^{\frac{1}{\sigma_{c}}-1}\right)^{-\sigma_{c}}$, which is trivially independent of $R_{t+2}$ under logarithmic preferences for consumption. The interpretation of those results is straightforward. Higher wages traditionally induce 2 well-identified, competing effects: a positive income effect, increasing both consumption and leisure (and thus decreasing labor supply), and a substitution effect stemming from the increase in the opportunity cost of leisure, hence favorable to labor supply. These 2 opposite effects have the same magnitude when $\sigma_{c}=1$, and thus just offset each other in such a parametric case. Since labor supply is then unaffected, so is the fertility decision given the optimality condition (5). Similarly, when the interest rate $R_{t+2}$ goes up, two effects emerge. Intertemporal substitution favors labor supply, as before. At the same time, the relative price of future (senior) consumption with respect to

\footnotetext{
${ }^{10}$ In that way, it is important to notice that the "insurance effect" we describe in our model is somewhat different from the one depicted in Kalemli-Ozcan (2003, 2008a), where it is the uncertain survival of adolescents that will trigger a precautionary demand for children, reflecting an insurance mechanism against more tardive deaths that cannot be easily replaced. As already signalled, we are closer to the mechanisms described in Kalemli-Ozcan (2008b).
} 
present (young adult) consumption falls down as the interest rate rises, which goes against extra savings and labor supply. Again, both effects exactly compensate each other under logarithmic preferences for consumption.

Things are apparently much trickier once we allow for the "wage effect" and the "interest rate effect" to be active, i.e. for $\sigma_{c} \neq 1$. The next proposition summarizes the associated properties.

Proposition 4 For logarithmic preferences in consumption $\left(\sigma_{c}=1\right)$, the optimal fertility and labor decisions are insensitive to wages and interest rate. For any $\sigma_{c}$ positive and not equal to 1 , an increase in the wage $w_{t+1}$ raises labor supply $l_{t+1}$ and reduces fertility $n_{t+1}$, if and only $\sigma_{c}<1$. A rise in the interest rate $R_{t+2}$ has the same properties.

Proof: Let us start with wages. Recall equation (13):

$$
\alpha_{1}\left(q_{t+1} n_{t+1}\right)^{-\sigma_{n}}=\theta \alpha_{2}\left[1-\theta q_{t+1} n_{t+1}-\Omega_{t+2}^{-\frac{1}{\sigma_{c}}} w_{t+1}^{\frac{1}{\sigma_{c}}-1}\left(q_{t+1} n_{t+1}\right)^{\frac{\sigma_{n}}{\sigma_{c}}}\right]^{-\sigma_{l}} .
$$

While the left-hand side is unaffected by wages, the right-hand side is. One can trivially see that the direction of the shift induced by an increase in wages is entirely determined by the position of $\sigma_{c}$ with respect to 1 . If (and only if) $\sigma_{c}<1$, an increment in wages increases the right-hand side, which leads to a drop in optimal fertility to re-establish equation (13). The optimal labor supply response is slightly trickier to characterize, since both sides of equation (11) are affected by an increase in wages:

$$
\frac{\alpha_{1}}{\Omega_{t+2}} w_{t+1}^{1-\sigma_{c}} l_{t+1}^{-\sigma_{c}}=\theta \alpha_{2}\left[1-\theta \Omega_{t+2}^{\frac{1}{\sigma_{n}}} w_{t+1}^{\frac{\sigma_{c}-1}{\sigma_{n}}} l_{t+1}^{\frac{\sigma_{c}}{\sigma_{n}}}-l_{t+1}\right]^{-\sigma_{l}} .
$$

Suppose the wage $w_{t+1}$ is rising and $\sigma_{c}<1$. The left-hand side is shifted upwards, which induces labor supply to increase to re-establish the equality (since, again, the left-hand side is decreasing in $\left.l_{t+1}\right)$. However, the right-hand side is also affected: it is actually shifted downwards, which again induces a further increase in labor supply since the right-hand side is increasing in $l_{t+1}$. We get the opposite picture if $\sigma_{c}>1$. As far as the interest rate is concerned, it can be readily established that when $R_{t+2}$ increases, the term $\Omega_{t+2}=\frac{\alpha_{1}}{\theta}\left(1+p_{t+1} \alpha_{3}^{\frac{1}{\sigma_{c}}} R_{t+2}^{\frac{1}{\sigma_{c}}-1}\right)^{-\sigma_{c}}$ goes in the opposite direction if and only if $\sigma_{c}<1$. To conclude about the impact of higher interest rates on optimal fertility and labor supply, it is enough to observe that $p_{t+1}$ and $R_{t+2}$ have the same effect on $\Omega_{t+2}$ if and only if $\sigma_{c}<1$. In the latter case, an increase in $R_{t+2}$ lowers $\Omega_{t+2}$, which generates the same effects on fertility and labor supply as increasing $p_{t+1}$. By Proposition 2, and reversing its statement, we must have a decrease in fertility $n_{t+1}$ and an increment in labor supply. $\square$

The obtained results deserve a careful interpretation. Let us focus on the wage effect. An increase in wages induces a classic positive income effect, which tends to increase consumption (in both periods), leisure and the number of children. However, in our model an increase in the number of children and an increase in leisure are detrimental to each other : henceforth, the positive income effect has a non-trivial impact on fertility. On the other side, the other classic effect of higher wages is the substitution effect, increasing the opportunity cost of both leisure and rearing children. We thus get the typical opposition between income and substitution effects à la Kremer and Chen (2002), which has in general an ambiguous effect on fertility. ${ }^{11}$

\footnotetext{
${ }^{11}$ It should be noted that Kremer and Chen (2002) directly choose a quasi-linear utility function for the substitution effect to dominate the income effect.
} 
A key departure from Kremer and Chen (2002) is the intertemporal nature of our model. This characteristic is crucial, since it will readily enable us to understand the preeminent role of the preference parameter $\sigma_{c}$. Indeed, in our story, individuals can take advantage of this wage increase in $t+1$ and only in $t+1$ : by increasing their labor supply to take advantage of higher wages in $t+1$, they can transfer consumption to their old age in $t+2$. Since the strength of intertemporal substitution in consumption is measured by $\frac{1}{\sigma_{c}}$, the lower $\sigma_{c}$, the more individuals will be willing to transfer consumption to $t+2$, the more they will work, and the lower leisure and fertility will be (via the needed reduction in the time devoted to rearing children). In our model, the "threshold" value for $\sigma_{c}$ is just one, that is logarithmic preferences in consumption (in both ages): below this threshold, individuals work more and have less children, and above, we have the opposite picture. We have a similar picture in the case of the interest rate. ${ }^{12}$

\subsection{Summary and relation to the fertility ambiguity under epidemic shocks}

Our simple model neatly illustrates why an epidemic shock has an ambiguous effect on fertility and labor supply. Indeed, if we interpret an epidemic shock as having direct consequences on survival probabilities and prices (for example on wages via the associated large cuts in labor supply), then our model shows that the total effect on fertility is a priori ambiguous when $\sigma_{c}<1$. On one side, a drop in both adult and children survival probabilities increases fertility, adding to the well-known insurance effect put forward by Kalemli-Ozcan (2002) in the case of child mortality a life-cycle mechanism linking adult mortality to fertility decisions. On the other side, under certain parametric conditions, the increase in wages resulting from labor shortage has the exact opposite effect on fertility, i.e. decreasing it. If the interest rates also move, then a third effect has to be accounted for. As shown in Proposition 4, if the interest rates go up following an epidemic shock, then it will reinforce the wage effect described above, inducing a larger drop in fertility. ${ }^{13}$

Whether the wage effect, neatly identified in our theory, can actually more than offset the mortality effect on fertility, as claimed by Young (2005) and questioned by Kalemli-Ozcan (2008a), is a crucial question that should deserve the maximal attention. However we have so far only studied optimal labor supply and fertility responses to exogenous shocks in prices. We shall now take a step further in the next section by closing the model and studying a general equilibrium version in which both wages and interest rates are endogenously determined. The main result of this section will outline the contrasting implications of child Vs adult mortality in general equilibrium, which will provide a kind of theoretical synthesis of Young's and Kalemli-Ozcan's approaches.

Finally, before moving to the characterization of these general equilibrium results, it is important to recall that one could extend the analysis conducted on fertility (and labor supply) to education. If the typical trade-off quality vs quantity of children were introduced in the model, the wage effect of epidemics would have implied an increasing quality of children (that is, more education) as the number of children goes down. Hence, the increase in the opportunity cost

\footnotetext{
${ }^{12}$ Note that the simple results obtained (which themselves derive from the simplicity of the model) do not mean that the other elasticity parameters are unimportant. One can for example notice that if $\sigma_{l}$, the elasticity of (marginal) utility of leisure with respect to the level of leisure, is increasingly large, the magnitude of the increase in labor supply will definitely get lower (in the case $\sigma_{c}<1$ ). We will however not comment further, since the focus of our model concerns the implication of price shocks on optimal fertility behavior.

${ }^{13}$ And it will be demonstrated in the next section that indeed, in the general equilibrium framework both wages and interest rates are likely to increase.
} 
of rearing children, directly induced by the rise in wages, should increase educational attainment along with decreasing the fertility rate. The mortality effects yield the opposite outcomes. Again, the total effect on education depends on the strength of the price effects relative to the mortality effects.

\section{Rational behavior under epidemics: accounting for gen- eral equilibrium effects}

In what follows, we place ourselves in the parametric case $\sigma_{c}<1$, for which the wage effect has been shown to operate in the direction opposite to the mortality effects in the previous section. Consistently with Zhang and Zhang (2005), we assume a production function of the Cobb-Douglas type:

$$
Y_{t}=K_{t}^{\alpha}\left(l_{t} L_{t}\right)^{1-\alpha},
$$

where $K_{t}$ is the stock of capital available in period $t, L_{t}$ the size of active population (assumed homogenous) and $\alpha$ is the capital share. We shut down technological progress. We finally assume full capital depreciation in one period, such that at equilibrium, one should ensure that:

$$
K_{t+1}=L_{t} s_{t}
$$

Under perfect competition, the production factors are paid at their marginal productivities, which yields the two following price equations:

$$
w_{t}=(1-\alpha)\left(\frac{K_{t}}{l_{t} L_{t}}\right)^{\alpha}
$$

and

$$
R_{t}=\alpha\left(\frac{K_{t}}{l_{t} L_{t}}\right)^{\alpha-1}
$$

To close the model, we finally need to observe that active population evolves according to the following law of motion:

$$
L_{t+1}=q_{t} n_{t} L_{t}
$$

Indeed, people working in $t+1$ are those who are young adults in $t+1$, which therefore were children in period $t$. Abstracting away from child mortality, the number of children in period $t$ is equal to the number of surviving young adults (who are the $L_{t}$ workers in that period) times fertility of this generation, which is equal to $n_{t}$. Accounting for child mortality gives the demographic law of motion just above.

In our behavioral equations (11) to (13), the relevant prices for the generation born in $t$ are $w_{t+1}$ and $R_{t+2}$. Using the equations (14) to (17) within our general equilibrium extension, one obtains the following expressions for the two relevant prices:

$$
w_{t+1}=(1-\alpha)\left(\frac{K_{t+1}}{l_{t+1} L_{t+1}}\right)^{\alpha}=(1-\alpha)\left(\frac{s_{t}}{q_{t} n_{t} l_{t+1}}\right)^{\alpha}
$$

and

$$
R_{t+2}=\alpha\left(\frac{K_{t+2}}{l_{t+2} L_{t+2}}\right)^{\alpha-1}=\alpha\left(\frac{s_{t+1}}{q_{t+1} n_{t+1} l_{t+2}}\right)^{\alpha-1}
$$


Equations (18) and (19) are enough to gather a very important result concerning child mortality.

Proposition 5 In general equilibrium, an increase in child mortality via a decrease in $q_{t+1}$ has no impact on equilibrium prices, $w_{t+1}$ and $R_{t+2}$. Therefore, a rise in child mortality does unambiguously raise fertility in general equilibrium.

Indeed, a fall in $q_{t+1}$ has not impact on $q_{t+1} n_{t+1}, l_{t+1}$ and $s_{t+1}$ by Proposition 3. From (18), it follows that it has no impact on the wage $w_{t+1}$. A priori, $q_{t+1}$ may impact $R_{t+2}$ via the term $l_{t+2}$ in equation (19). Indeed, writing equation (11) one period ahead, one can see that $l_{t+2}$ does depend on $w_{t+2}$, which itself depends on $q_{t+1}$ according to:

$$
w_{t+2}=(1-\alpha)\left(\frac{K_{t+2}}{l_{t+2} L_{t+2}}\right)^{\alpha}=(1-\alpha)\left(\frac{s_{t+1}}{q_{t+1} n_{t+1} l_{t+2}}\right)^{\alpha}
$$

but again, here Proposition 3 is enough to conclude that such an effect is neutralized thanks to the presence of the product $q_{t+1} n_{t+1}$, which is independent of $q_{t+1}$. So $l_{t+2}$ is unaffected by changes in the probability $q_{t+1}$, which leaves the interest rate $R_{t+2}$ also unaffected. Therefore, chld mortality has no general equilibrium price effect, and an increase in such a mortality unambiguously brings up fertility consistently with Kalemli-Ozcan (2003, 2008a).

Things are definitely trickier for adult mortality, as reflected in the following proposition.

Proposition 6 In general equilibrium, an increase in adult mortality via a decrease in $p_{t+1}$ cause wages $w_{t+1}$ to unambiguously go up. Therefore, a rise in adult mortality has an ambiguous effect on fertility in general equilibrium.

The possible opposite directions of the wage and adult mortality effects on fertility behavior had already been extensively commented in our partial equilibrium analysis, where positive shocks on prices were exogenously imposed. This property is here crucially shown to hold in general equilibrium too. Indeed, by equation (18), one can immediately see that a drop in $p_{t+1}$, causing labor supply $l_{t+1}$ to decrease under fixed prices (by Proposition 2), will further induce an increase in wages. Such an increment in wages plays against fertility, and this "second-round" effect may counter-balance and possibly outweigh the direct positive effect of the adult survival probability drop on the same variable.

We deem the results stated in proposition 5 and 6 as highly relevant for the ongoing debate about the overall impact on fertility of epidemics such as the one of HIV/AIDS. Indeed, showing that the impact of a rise in child mortality on optimal fertility behavior is unambiguously positive through the absence of effect on prices (and particularly wages) at equilibrium (proposition 5) is indeed consistent with Kalemli-Ozcan (2002, 2008a), but also shows that the opposition between mortality effect and wage effect does not hold in the case of child mortality. It hence demonstrates that the initial debate between Kalemli-Ozcan and Young (Kalemli-Ozcan, 2008a) is somewhat flawed, since the "insurance effect" channel had so far been argued to counteract the wage effect: we show that the two effects do not stem from the same type of mortality shock, since the first one is associated to child mortality, while the second only arises in the case of adult mortality (proposition 6). In our view, disentangling and even isolating in such a way the two effects is a key result, once we consider that the mortality age profiles for major epidemics (Black Death, Spanish flu or AIDS) rather exhibit the preeminence of adult mortality. ${ }^{14}$ The debate should

\footnotetext{
${ }^{14}$ Recent demographic projections (see, for example, the UNAIDS (2004) annual report) are nevertheless showing quite an alarming trend for HIV-related child mortality in some Sub-Saharan African countries for the next two decades. However, it is undisputable that the vast majority of AIDS-related deaths are active adults.
} 
then rather focus on the opposing positive direct effect of adult mortality on fertility behavior (through the previously identified life-cycle channel ${ }^{15}$ ) and the negative, "second-round" effect triggered by the resulting endogenous increase in wages. Our model shows that if the wage effect associated to this kind of mortality shock is strong enough, then the optimal fertility decision might end up being reduced, and not augmented by the epidemics.

One should also notice this last possibility is even more likely if the interest rate effect ends up reinforcing the wage effect. From equation (19), one can see that the interest rate is also likely to go up after the adult epidemic shock because a drop in $p_{t+1}$ lowers savings, $s_{t+1}$ and increases fertility, $n_{t+1}$ by Proposition 2: Both moves increase the interest rate $R_{t+2}$, which by Proposition 4, reinforces the above outlined wage effect.

Unfortunately, it is not possible to bring out analytical results characterizing finely when the wage effect does dominate the direct mortality effect on fertility, neither in the short run nor in the stationary equilibrium. The model is certainly solvable in general equilibrium under logarithmic preferences, but as already outlined before this case is uninteresting as far as the question at hand is concerned, since it neutralizes the prices effects on optimal decisions (as properly shown in Proposition 4). Rather than looking at rough calibrations of the model, we now complement our theoretical analysis with an empirical analysis, applied to the HIV/AIDS Sub-Saharan case. We will hence see that in this particular epidemic episode, the negative wage effect on fertility indeed seems to dominate the positive life-cycle effect in the case of an increase in adult mortality.

\section{Empirical analysis}

Our empirical specification will focus on differentiating the two possible different mortality channels (child and adult mortality) that can arise in an epidemic shock, and on exemplifying their different overall impact on fertility behavior. This precise identification of the role of the two different mortality shocks will enable us to finally tackle the overall impact of HIV, that has been found to influence the fertility behavior through both the child and adult mortality channels.

\subsection{Empirical model and data}

In addition to mortality, fertility should be influenced by education, real income per capita and conflict occurrence. A higher average number of schooling years is likely to increase the opportunity cost of childbearing for women, hence education is expected to have a negative impact on the fertility rate. Similarly, the net costs of childrearing, e.g. housing, nursing and training costs, tend to be higher in more developed countries displaying a higher level of real income per capita (Becker, 1992). Last, conflict occurrence may decrease the willingness or the feasibility of having children since current and future upbringing conditions may not be perceived as optimal (Agadjanian and Prata, 2001). The following model will therefore be estimated:

$$
\begin{aligned}
\text { Total fertility } \operatorname{rate}_{i}^{t}= & \beta_{1} \operatorname{Ln}(\text { Child mortality })_{i}^{t}+\beta_{2} \operatorname{Ln}(\text { Adult mortality })_{i}^{t} \\
& +\beta_{3} \operatorname{Ln}(\text { Real GDP per capita })_{i}^{t}+\beta_{4} \text { Education }_{i}^{t}+\beta_{5} \text { Conflict occurrence }_{i}^{t} \\
& +\mathrm{T}^{t}+\epsilon_{i}^{t}
\end{aligned}
$$

\footnotetext{
${ }^{15}$ As well acknowledged by Kalemli-Ozcan (2008a) along with Soares (2005).
} 
where $T^{t}$ are country-invariant time-specific $t$ fixed effects and $\epsilon_{i}^{t}=C_{i}+v_{i}^{t}$, with time-invariant country-specific $i$ fixed effects $C_{i}$ and idiosyncratic shocks $v_{i}^{t}$. As previously stated and in line with our theoretical model, fertility is expected to be positively influenced by child mortality and negatively influenced by income per capita, education and the occurrence of a territorial conflict. The impact of adult mortality on the other hand is ambiguous.

The total fertility rate is the number of children that a woman would have if she lived through all of her child-bearing years and experienced the current age-specific fertility rates at each age. Data come from the United Nations Population Division (2007). Child mortality (rate per 1000 live births) is defined as the probability of dying before age 5, if subject to current age-specific mortality rates. Data come from the World Health Organization. Adult mortality rate is the probability of dying between the ages of 15 and 60 years (per 1000 population) per year, if subject to the age-specific mortality rates of the reporting year. Data on male and female adult mortality rates come from the World Bank (2007) and have been combined into an average mortality rate by weighing each mortality rate by the gender share in the active population. Real GDP per capita and education, the latter measured by average schooling years in population aged 25 or over, come from Baier et al. (2006). Finally, the armed conflicts dataset developed by Uppsala University (Eriksson and Wallensteen, 2004) provides a measure of the intensity and length of a territorial conflict. The conflict occurrence variable takes the value of 1 if a minor armed conflict occurs, 2 if an intermediate armed conflict occurs, 3 if a war occurs, on the country's territory. For ease of interpretation the variable has been re-scaled from range 0 to 1.

Data on the total fertility rate are reported as five year averages by the UNPD. Hence, a fiveyear period panel covering the apparition and spread of the HIV epidemic in Sub-Saharan Africa is constructed. The quinquennial periods are 1980-1984, 1985-1989, 1990-1994, 1995-1999, 20002004. However, besides the data on conflict occurrence, which are available for consecutive years and have been averaged over each five-year period, values of other variables are only available for the years 1980, 1990 and 2000. Hence they have been interpolated in order to obtain beginning of period values for 1985 and 1995. In Appendix 1, it is shown that the results of this paper hold when using non-interpolated ten-year period panel data from 1960 to 2004.

Concerns about the reliability of the data may be raised. The data generated by Baier et al. (2006) have been rarely used in the literature and mortality rates, especially those of the adult population, are certainly measured with substantial error. Therefore, as commonly done in the literature on the growth impact of education (see for instance Cohen and Soto (2007)), reliability indicators measuring the signal-to-total variance ratio of a variable have been constructed. They can be found in Appendix 2. They show that the informational content of the data series used in this paper is very high, even when expressed in changes, and that the spatio-temporal coverage of other data sources is much narrower.

The only two channels identified by our model through which the disease should have an effect on fertility are the child mortality channel and the adult mortality channel. A simple way of testing such a hypothesis is to directly include a measure of HIV prevalence in equation 1. An absence of significance of its coefficient will be consistent with a model in which the effect of HIV is completely transmitted through the mortality variables. On the other hand, significance will imply that HIV prevalence exerts a direct effect on fertility, beyond its impact on mortality. Time-series data on HIV prevalence in adult population, the percentage of people aged 15-49 who are infected with HIV, have been obtained from Karen Stanecki, UNAIDS senior epidemiologist. The time series have been estimated in November 2006 with the use of the UNAIDS Estimation 
and Projection Package (EPP) 2005, which fits an epidemic model to all available estimates of HIV prevalence in order to produce a country-specific epidemic curve that describes the evolution of adult HIV prevalence rates over the $1980-2005$ period. ${ }^{16}$ Since the time-series for each country have been generated at the same time they are not plagued by temporal inconsistency caused by changes in assumptions, methodologies and data used. However, one major limitation of the EPP is related to the non-representative nature of the data used since estimates of HIV prevalence in adult population are mainly derived from data on the proportion of seropositive females among pregnant women attending urban or peri-urban antenatal clinics. Potential biases associated with the use of antenatal clinic data include the selection for sexual activity and absence of contraceptive use, the lower fertility of HIV-infected women, the joint determination of antenatal clinic attendance and HIV status, the under-representation of smaller rural sites in surveillance systems and how well prevalence levels among pregnant women represent those among men (Walker et al., 2004). Where countries' surveillance systems do not cover adequately rural areas, in which HIV prevalence is expected to be lower than in urban areas, the non-urban prevalence produced by the EPP is adjusted downwards by $20 \%$ to reflect this bias. Adjustments for expansion of surveillance systems into lower prevalence areas and for turnover in concentrated epidemics are also implemented. Finally and most importantly, when general population survey data are available, trends fitted from antenatal data have been recalibrated to adjust urban and rural HIV levels to those measured in the population-based survey. In appendix 1, it is shown that these estimates of HIV prevalence appear reliable, certainly because the calibration of the data to national population surveys had occurred for most of the countries included in the data used in the reliability analysis. ${ }^{17}$ Hence, the robustness of the results will be assessed by either interacting the HIV variable with a dummy which takes the value of one when the prevalence rate has been adjusted, or by restricting the sample to the countries for which calibration has occurred.

Data are available for 39 SSA countries over the 1980-2004 period. Summary statistics are given in tables 1 and 2. Several regressions diagnostics have been carried out. According to a Cook's D test, influential outliers have been removed from the sample, Ramsey (1969)'s RESET or Pregibon (1980)'s Link tests suggests that the model is well specified and the low value of the mean variance inflation factor indicates that multicollinearity is not a problem. However, most variables in equation 1 are likely to be endogenous to the fertility rate and undoubtedly measured with error. ${ }^{18}$ To correct both biases in the context of panel data models, when no obvious external instruments are available, internal instruments based on the lags of the instrumented variables can be used. This can be done through the use of the "system-GMM" estimator (Arellano and Bover, 1995; Blundell and Bond, 1998). Equation 1 will be simultaneously estimated in first difference and level and to ensure consistent estimates of the coefficients, the equation in firstdifference (level) will be instrumented by the lagged levels (first-differences) of the variables.

\footnotetext{
${ }^{16}$ See Ghys et al. (2004) and Brown et al. (2006) for a clear presentation of the EPP. The approach is different for low-level or concentrated epidemics in which HIV is concentrated in groups with high-risk behaviours. For these epidemics, where the HIV prevalence rate is considered to be below $1 \%$ in pregnant women in urban areas, because transmission is assumed to occur mainly in groups at high risk of HIV infection, estimates for populations who are most exposed to HIV/AIDS are combined to produce an overall estimate of adult prevalence (Lyerla et al., 2006).

${ }^{17}$ Nevertheless, note that Grassly et al. (2004) show that estimates based on antenatal sentinel surveillance provide a good approximation of HIV prevalence in adults in the local community and Young (2007), using antenatal and community data for 50 regions in 8 African countries, does not find a significant difference between community and antenatal infection rates.

${ }^{18}$ Note that measurement errors constant over time but specific to each country will be absorbed into the time-invariant country specific effects.
} 


\begin{tabular}{|c|c|c|c|c|c|}
\hline Variable & Mean & Std. Dev. & Min. & Max. & $\mathrm{N}$ \\
\hline Fertility & 5.99 & 1.16 & 1.91 & 8.10 & 185 \\
\hline Average years of schooling & 3.02 & 1.87 & 0.33 & 8.60 & 185 \\
\hline Child Mortality $_{l n}$ & 5.10 & 0.46 & 3.00 & 5.82 & 185 \\
\hline Adult Mortality $_{l n}$ & 6.03 & 0.22 & 5.16 & 6.60 & 185 \\
\hline Real GDP per capita $l n$ & 6.81 & 0.65 & 5.74 & 8.83 & 185 \\
\hline Territorial conflict & 0.18 & 0.31 & 0.00 & 1.00 & 185 \\
\hline HIV prevalence $_{l n}$ & 1.00 & 0.95 & 0.00 & 3.39 & 185 \\
\hline HIV prevalence adjusted ${ }_{l n}$ & 1.11 & 0.96 & 0.00 & 3.39 & 95 \\
\hline
\end{tabular}

Table 1: Summary statistics

Under the assumption that these lagged values are not correlated with the error term, they will be appropriate instruments. The validity of the instruments will be tested through Hansen (1982) tests of over-identifying restrictions and an Arellano and Bond (1991) test of serial correlation of the differenced error term. In order not to overfit the instrumented variables, which may bias the results towards those of an uninstrumented regression and weaken the Hansen tests, the GMM instruments are restricted to period $t-2(t-1)$ lagged levels (first-differences) of each variable for the first-difference (level) equation. ${ }^{19}$ In addition, robustness of the results to the number of instruments will be investigated by collapsing the number of instruments, i.e. the instrument set will only contain two instruments per instrumented variable instead of including all available valid lags (see Roodman (2007)).

\footnotetext{
${ }^{19}$ Roodman (2004) indicates as a rule of thumb that the number of instruments should not exceed the number of countries in the regression.
} 


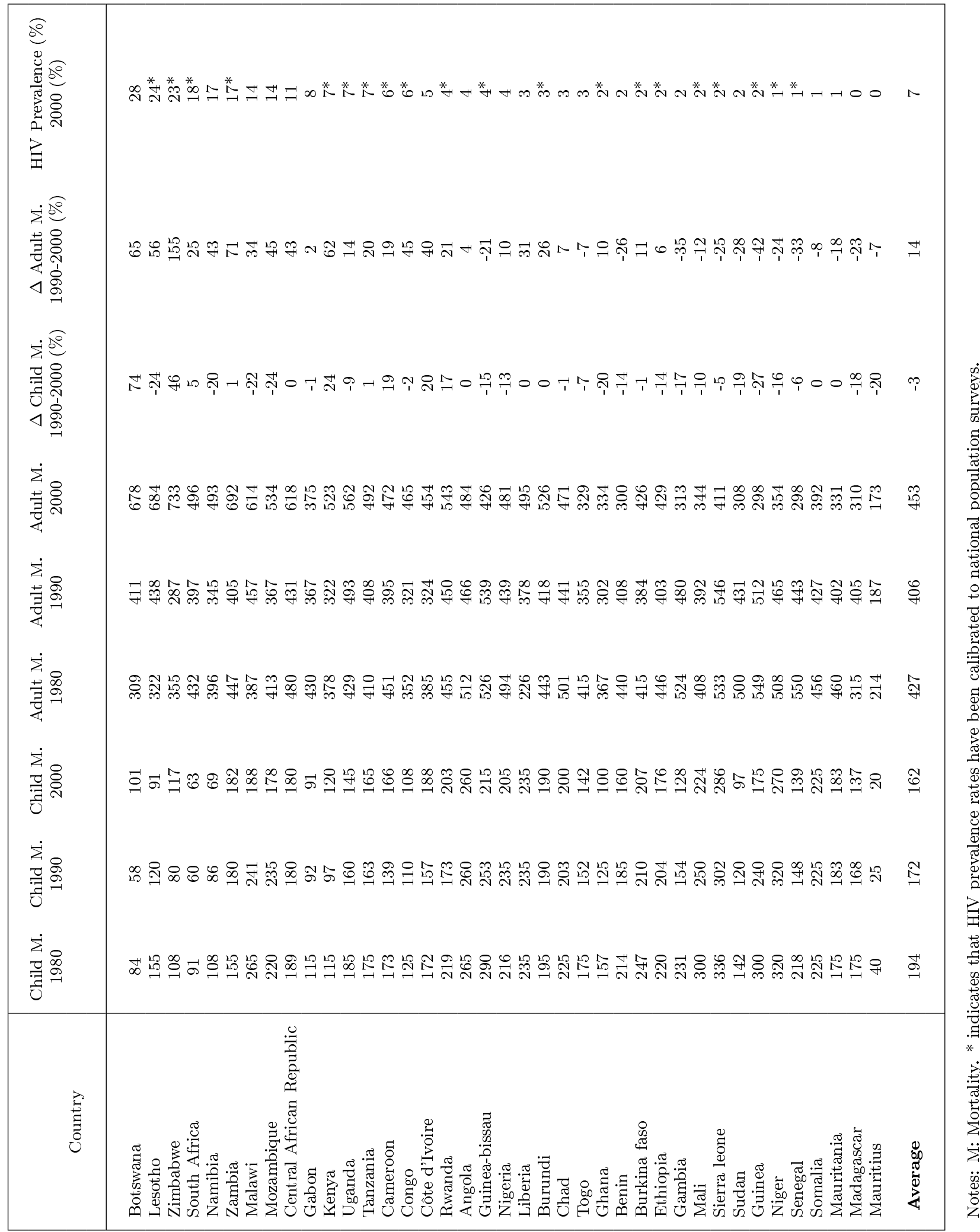




\subsubsection{Results}

Results are presented in table 3. The validity of the instruments is never rejected, all control variables have the expected sign and most of them are significant. ${ }^{20}$ In line with our theoretical model, child mortality exerts a positive impact on fertility whereas we empirically find that the opposite is true for adult mortality (column 1). Columns 2 and 3 show that the impacts of male adult mortality rate and female adult mortality on fertility are about the same. Finally, in column 4 , the sensitivity of results and specification tests to a reduction in the number of instruments is investigated by "collapsing" the instruments. Although the efficiency of the regression estimates decreases, results are fairly unaffected by this robustness check, at the exception of the territorial conflict variable, whose negative effect becomes highly significant.

Kalemli-Ozcan (2008a) finds that the logarithm of the HIV prevalence exerts a direct positive effect on fertility, beyond the HIV-related rise in infant mortality. This issue is investigated in table 4. Keeping the instruments collapsed, the logarithm of the HIV prevalence rate is included among other determinants of fertility in column $5 .^{21}$ Its coefficient is indeed positive but small and highly insignificant. However the reliability of HIV prevalence rates not calibrated to national population surveys is questionable. Robustness of these results are therefore examined by either interacting the HIV variable with a dummy which takes the value of one when the prevalence rate has been adjusted (column 6) or by restricting the sample to the countries for which calibration has occurred (column 7). In both cases, the null of a direct impact of HIV prevalence on fertility cannot be rejected. ${ }^{22}$ Column 7 shows that even with half the initial sample, variables of interest remain significant with the expected sign and it cannot be rejected that their coefficients equal the estimates obtained in column (1). The absence of a direct impact of HIV prevalence suggests that the mortality channels capture reasonably well the total effect of this disease on fertility.

In order to estimate the full impact of a rise in HIV prevalence on fertility through both child and adult mortality channels, simple finite distributed lag models are estimated. It makes sense to allow for lagged effects of HIV prevalence on mortality since full progression from infection to AIDS death in the absence of competing causes of mortality takes at maximum about 10 years in the case of children, which are not necessarily born at the time of the maternal infection, and 15-20 years in the case of adults (Stover, 2004). As a benchmark, a finite distributed lag model of order 3 is first estimated and afterwards, the appropriate number of lags is chosen according

\footnotetext{
${ }^{20}$ Other variables, included in Conley et al. (2006) or Kalemli-Ozcan (2008a) have been tested: population density, urbanisation rate, area-weighted Green Revolution modern variety crops. None was found to be significant.

21 ' 1 ' has been added to the HIV prevalence rate in order to deal with zero values ( $15 \%$ of observations for the period 1980-1984).

${ }^{22}$ As another robustness check, the instrumental variable strategy of Kalemli-Ozcan (2008a) was adopted. We ran between regressions, with the logarithm of the HIV prevalence instrumented by the distance from the capital city of each country to the capital city of the Democratic Republic of Congo, alleged birthplace of the epidemic. The coefficient of the HIV prevalence rate remained insignificant and the validity of the instrument was rejected by the Cragg-Donald F statistic. The positive impact found by Kalemli-Ozcan (2008a) may result from the fact that distance from the Democratic Republic of Congo is positively correlated with the share of muslims in total population in $1980(r=0.54)$. Thanks to circumcision, muslims may have lower HIV prevalence than non-Muslims and their religious beliefs may positively affect their fertility behaviour. As pointed out by Murray (2006), an instrumental variable strategy is no more valid if a variable correlated with either the endogenous variable or the instrument has been omitted from the econometric model. In first-stage regressions, the share of muslims in total population entered significantly with a negative sign and once this variable was included, the bilateral distance was found to be not significant any more, suggesting indeed an omitted variable bias. It should further be noted that even if a good instrument could be found for HIV prevalence, estimators will still be biased and inconsistent if other determinants of fertility are endogenous.
} 


\begin{tabular}{|c|c|c|c|c|}
\hline \multirow{2}{*}{ Determinants } & \multicolumn{4}{|c|}{ Fertility } \\
\hline & (1) & $(2)$ & $(3)$ & $(4)$ \\
\hline Child mortality $_{l n}$ & $\begin{array}{l}1.07^{a} \\
(0.25)\end{array}$ & $\begin{array}{l}1.08^{a} \\
(0.27)\end{array}$ & $\begin{array}{l}1.08^{a} \\
(0.23)\end{array}$ & $\begin{array}{l}1.06^{b} \\
(0.45)\end{array}$ \\
\hline Adult mortality $l n$ & $\begin{array}{l}-0.60^{b} \\
(0.23)\end{array}$ & & & $\begin{array}{l}-0.54^{c} \\
(0.32)\end{array}$ \\
\hline Male adult mortality ${ }_{l n}$ & & $\begin{array}{l}-0.62^{b} \\
(0.25)\end{array}$ & & \\
\hline Female adult mortality ${ }_{l n}$ & & & $\begin{array}{l}-0.58^{a} \\
(0.23)\end{array}$ & \\
\hline Real GDP per capita $l n$ & $\begin{array}{l}-0.57^{a} \\
(0.13)\end{array}$ & $\begin{array}{r}-0.55^{a} \\
(0.13)\end{array}$ & $\begin{array}{l}-0.59^{a} \\
(0.12)\end{array}$ & $\begin{array}{l}-0.66^{b} \\
(0.29)\end{array}$ \\
\hline Average years of schooling & $\begin{array}{l}-0.16^{a} \\
(0.04)\end{array}$ & $\begin{array}{l}-0.16^{a} \\
(0.04)\end{array}$ & $\begin{array}{l}-0.16^{a} \\
(0.04)\end{array}$ & $\begin{array}{l}-0.13^{c} \\
(0.07)\end{array}$ \\
\hline Occurrence of a territorial conflict & $\begin{array}{l}-0.16 \\
(0.21)\end{array}$ & $\begin{array}{l}-0.16 \\
(0.21)\end{array}$ & $\begin{array}{l}-0.17 \\
(0.21)\end{array}$ & $\begin{array}{l}-0.69^{a} \\
(0.34)\end{array}$ \\
\hline Constant & $\begin{array}{l}8.12^{a} \\
(1.34)\end{array}$ & $\begin{array}{l}8.17^{a} \\
(1.41)\end{array}$ & $\begin{array}{l}8.08^{a} \\
(1.33)\end{array}$ & $\begin{array}{l}8.34^{b} \\
(3.84)\end{array}$ \\
\hline Observations & 185 & 185 & 185 & 185 \\
\hline Countries & 39 & 39 & 39 & 39 \\
\hline Instruments & 35 & 35 & 35 & 15 \\
\hline Arellano-Bond test $\mathrm{AR}(1) \mathrm{p}$-value & 0.00 & 0.00 & 0.00 & 0.00 \\
\hline Arellano-Bond test $\operatorname{AR}(2)$ p-value & 0.63 & 0.56 & 0.72 & 0.99 \\
\hline Hansen overidentification test $\mathrm{p}$-value & 0.46 & 0.44 & 0.50 & 0.48 \\
\hline Difference-in-Hansen test level GMM p-value & 0.64 & 0.62 & 0.68 & 0.48 \\
\hline Difference-in-Hansen test IV p-value & 0.84 & 0.81 & 0.90 & 0.35 \\
\hline
\end{tabular}

Notes: $\mathrm{a}, \mathrm{b}, \mathrm{c}$ denotes respectively significance at the 1,5 and $10 \%$ level. ${ }_{l n}$ : variable in logarithms.

Standard errors are in parentheses. All GMM standard errors are heteroscedasticity- and

autocorrelation-robust and include the Windmeijer (2005) finite-sample correction. In regression

(4) instruments are collapsed. Unreported time dummies are included.

Table 3: Child mortality, adult mortality and fertility in Africa 


\begin{tabular}{|c|c|c|c|}
\hline \multirow{2}{*}{ Determinants } & \multicolumn{3}{|c|}{ Fertility } \\
\hline & $(5)$ & $(6)$ & $(7)$ \\
\hline \multirow[t]{2}{*}{ Child mortality ${ }_{l n}$} & $1.07^{a}$ & $1.17^{a}$ & $1.89^{b}$ \\
\hline & $(0.41)$ & $(0.37)$ & $(0.95)$ \\
\hline \multirow[t]{2}{*}{ Adult mortality ${ }_{l n}$} & $-0.62^{b}$ & $-0.64^{b}$ & $-1.03^{c}$ \\
\hline & $(0.29)$ & $(0.30)$ & $(0.53)$ \\
\hline \multirow[t]{2}{*}{ HIV prevalence ${ }_{l n}$} & 0.05 & 0.07 & 0.27 \\
\hline & $(0.10)$ & $(0.09)$ & $(0.24)$ \\
\hline Adjusted HIV prevalence dummy & & 0.09 & \\
\hline HIV prevalence $_{l n} *$ Dummy & & $\begin{array}{l}-0.03 \\
(0.12)\end{array}$ & \\
\hline \multirow[t]{2}{*}{ Real GDP per capita ${ }_{l n}$} & $-0.66^{a}$ & $-0.60^{b}$ & -0.37 \\
\hline & $(0.25)$ & $(0.25)$ & $(0.32)$ \\
\hline \multirow[t]{2}{*}{ Average years of schooling } & $-0.14^{c}$ & $-0.14^{c}$ & -0.16 \\
\hline & $(0.07)$ & $(0.07)$ & $(0.15)$ \\
\hline \multirow[t]{2}{*}{ Occurrence of a territorial conflict } & $-0.70^{a}$ & $-0.69^{a}$ & -0.39 \\
\hline & $(0.24)$ & $(0.25)$ & $(0.40)$ \\
\hline Constant & $\begin{array}{l}8.73^{a} \\
(3.05)\end{array}$ & $\begin{array}{c}7.90^{a} \\
(2.66)\end{array}$ & $\begin{array}{c}4.86 \\
(6.17)\end{array}$ \\
\hline Observations & 185 & 185 & 95 \\
\hline Countries & 39 & 39 & 20 \\
\hline Instruments & 17 & 20 & 17 \\
\hline Arellano-Bond test $\mathrm{AR}(1) \mathrm{p}$-value & 0.00 & 0.00 & 0.05 \\
\hline Arellano-Bond test $\mathrm{AR}(2) \mathrm{p}$-value & 0.88 & 0.99 & 0.50 \\
\hline Hansen overidentification test p-value & 0.61 & 0.69 & 0.20 \\
\hline Difference-in-Hansen test level GMM p-value & 0.61 & 0.69 & 0.20 \\
\hline Difference-in-Hansen test IV p-value & 0.49 & 0.80 & 0.23 \\
\hline
\end{tabular}

Notes: $\mathrm{a}, \mathrm{b}, \mathrm{c}$ denotes respectively significance at the 1,5 and $10 \%$ level. ${ }_{l n}$ : variable in logarithms. Standard errors are in parentheses. All GMM standard errors are heteroscedasticity- and autocorrelation-robust and include the Windmeijer (2005)

finite-sample correction. In all regressions, instruments are collapsed. Unreported time dummies are included.

Table 4: Testing for a direct impact of HIV on fertility 
to the Bayesian Information Criterion (BIC). First differences are used in order to remove timeinvariant country-specific determinants of mortality, e.g. malaria. RESET and Link tests are reported in order to detect functional form mispecification or an omitted variable bias. The sample includes the 20 countries for which HIV prevalence rates have been calibrated to national population surveys ${ }^{23}$ and five-year interval data covering the 1980-2000 period are used. Results are reported in table 5 .

Table 5 shows that after selection of the most appropriate models it is found that the impact of a rise in HIV prevalence is not instantaneous. Depending on the mortality considered, it starts 5-10 years and stops 10-15 years after the initial rise. Unsurprisingly, the variance explained by changes in HIV prevalence is much higher in the case of adult mortality than in the case of child mortality. However, even in the latter case, the RESET and Link tests cannot reject the hypothesis that the model is well-specified. By combining the estimates of columns ( $\left.8^{\prime}\right)$ and $\left(9^{\prime}\right)$ of table 5 with those in column (1) of table 3, figure 1 shows the dynamic effect of a doubling of the HIV prevalence rate on fertility. The relationship between HIV and fertility with respect to time is v-shaped. In the short-run, i.e. five years after the rise in HIV prevalence, fertility decreases as adult mortality is the first one to increase in the case of such an epidemiologic shock. In the mid-run however, ten years after the shock, the contemporaneous effect of HIV on fertility is positive, as the child mortality channel is found to outweigh the adult mortality channel. Hence, the cumulative dynamic effect decreases. Finally in the long-run, fifteen years later, the contemporaneous effect of HIV on fertility is again negative, as only HIV-related adult mortality remains. This leads to a rise in the cumulative dynamic effect, whose ending value represents the long-run impact of a rise in HIV prevalence on fertility. For illustrative purpose, the right hand-side $\mathrm{Y}$ axis indicates the average value of the country-specific $\%$ decline in fertility with respect to a $1 \% \mathrm{pt}$ increase in HIV ${ }^{24}$ Under ceteris paribus conditions, the decline in fertility would be equal to $-0.93 \%,-0.73 \%$ and $-1.11 \%$ respectively 5,10 and 15 years after the initial shock.

These results tend to support the findings of Young (2005, 2007) since the long-term impact of a rise in HIV prevalence on fertility is strongly negative. It must be nevertheless emphasized that these results do not contradict the approach of Kalemli-Ozcan (2008a). A rise in HIV prevalence will clearly increase the precautionary demand for children and may even lead for a short period to a rebound of fertility. However, this effect will be eventually outweighed by the full impact of a rise in HIV prevalence on adult mortality. In contrast to the HIV disease, which affects the mortality of two distinct demographic groups, investigating the impact of an infectious disease such as malaria would have been much less controversial. Following a rise in malaria prevalence, the fertility would undoubtedly rise as more than $90 \%$ of its victims in Africa are children.

\section{Conclusion}

Theoretically, we studied the influence of mortality shocks in a general equilibrium framework allowing for price effects to arise. After having identified positive direct effects of both the child and adult mortality shocks in a partial equilibrium environment with fixed prices, we showed

\footnotetext{
${ }^{23}$ Results are virtually unchanged if the full sample is used.

${ }^{24}$ The sample corresponds to the countries for which HIV data have been calibrated to national population surveys and starting values for the fertility rate and the HIV prevalence rate correspond to the period 2000-2004.
} 


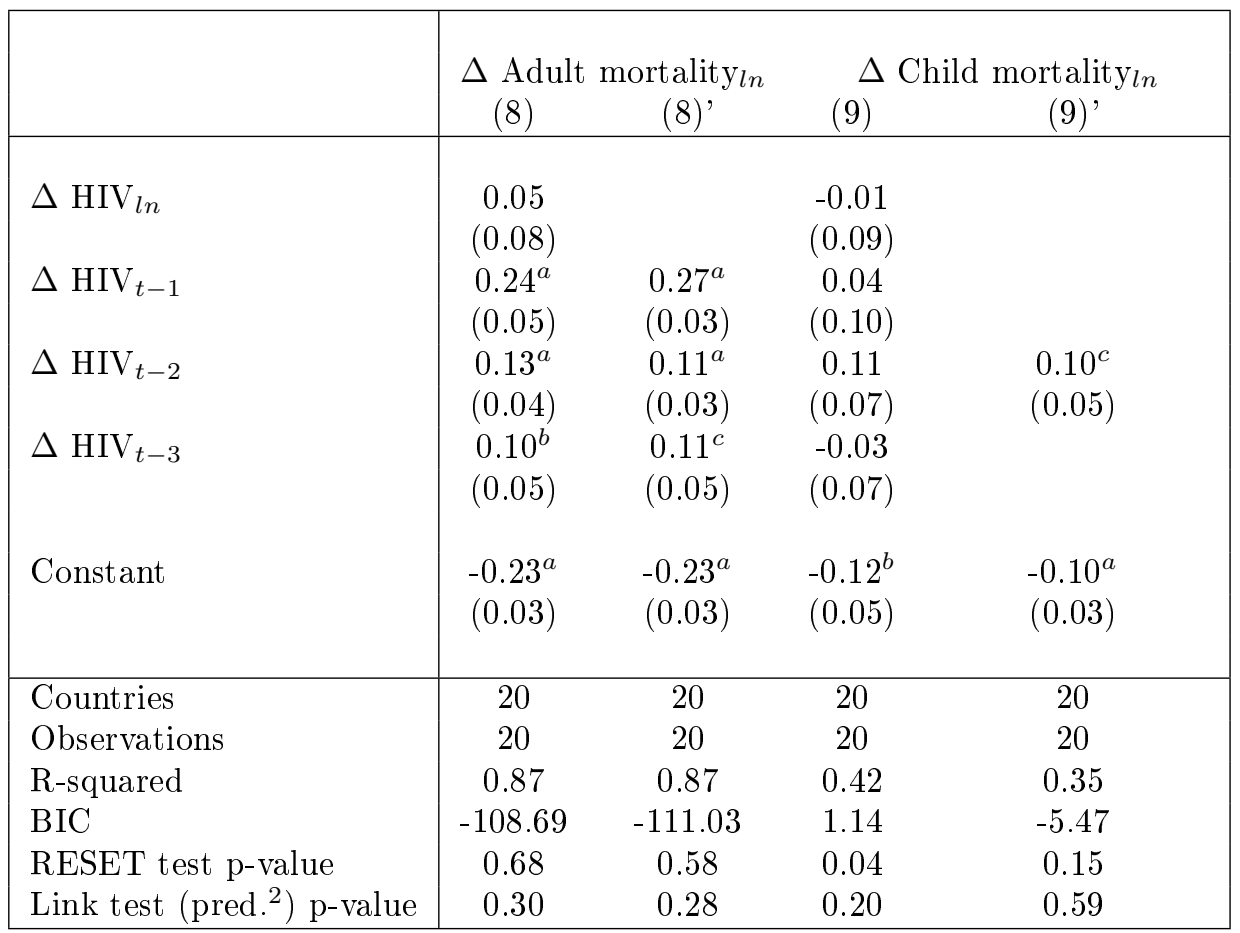

Notes: $\mathrm{a}, \mathrm{b}, \mathrm{c}$ denotes respectively significance at the 1,5 and $10 \%$ level. ${ }_{l n}$ : variable in logarithms. Robust standard errors are in parentheses.

Table 5: Dynamic effects of a rise in HIV prevalence on mortality

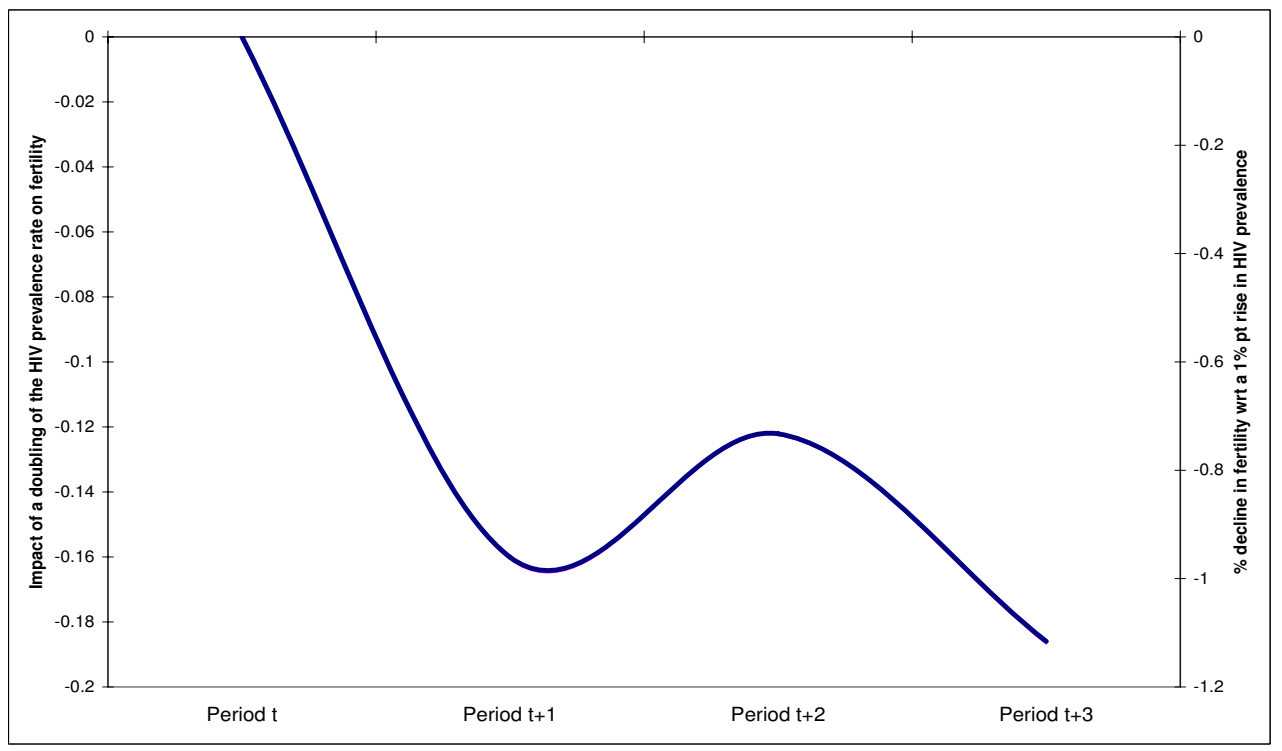

Figure 1: Cumulative dynamic impact of a rise in HIV prevalence on fertility 
the overall effects of those two types of mortality to deeply differ in a general equilibrium set-up. While the child mortality shock is found to exert an unambiguously positive overall effect on fertility through the absence of price effect, we demonstrated the ambiguous direction of the adult mortality effect on fertility because of the "second-round", negative wage effect. In order to determine whether the negative impact of the wage channel on fertility outweighs the direct, positive influence of an adult mortality shock, we then conducted an empirical analysis of the HIV/AIDS epidemic in the SSA case. While we confirm, along with the predictions of our theoretical model, that an increase in the child mortality rate exerts a robust positive impact on fertility, we also show that indeed, the reverse is true for adult mortality. We further find the child mortality positive effect on fertility (consistent with the argumentation of Kalemli-Ozcan (2008a)) to be eventually outweighed by the full impact of a rise in HIV prevalence on adult mortality, supporting the findings of Young (2005, 2007).

Last, even though we conclude, along with Young $(2005,2007)$, in a negative overall impact of the AIDS/HIV epidemic on fertility, it is however worth noting that our results do not imply that the HIV/AIDS epidemics is welfare-enhancing. Beyond the unfathomable effects of the dramatic cost in human lives, one can for example evoke the dire consequences of the growing number of orphans, and its detrimental effects on the level of inequalities in the economy (Boucekkine and Laffargue, 2007). However, our purpose in this work was to focus on a careful study of the behavioral consequences of epidemics such as HIV/AIDS, shedding light on the forces at play and their respective consequences, and opening the floor for use of such results in further studies on the overall economic impact of epidemics.

\section{References}

Agadjanian, Victor and Ndola Prata, "War and Reproduction: Angola's Fertility in Comparative Perspective," Journal of Southern African Studies, 2001, 27 (2), 329-347.

Ahmad, Omar B., Alan D. Lopez, and Mie Inoue, "The Decline in Child Mortality: A Reappraisal," Bulletin of the World Health Organization, 2000, 78 (10), 1175-1191.

Arellano, Manuel and Olympia Bover, "Another Look at the Instrumental Variable Estimation of Error-Components Models," Journal of Econometrics, 1995, 68 (1), 29-51.

- and Stephen Bond, "Some Tests of Specification for Panel Data: Monte Carlo Evidence and an Application to Employment Equations," Review of Economic Studies, April 1991, 58 (2), 277-97.

Baier, Scott L., Gerald P. Jr. Dwyer, and Robert Tamura, "How Important Are Capital and Total Factor Productivity for Economic Growth," Economic Inquiry, 2006, 44 (1), 23-49.

Becker, Gary S., "Fertility and the Economy," Journal of Population Economics, 1992, 5, 185-201.

Blacker, John, "The Impact of AIDS on Adult Mortality: Evidence From National and Regional Statistics," AIDS, 2004, 18 (S2), 19-26.

Blundell, Richard and Stephen Bond, "Initial Conditions and Moment Restrictions in Dynamic Panel Data Models," Journal of Econometrics, 1998, 87 (1), 115-143. 
Boucekkine, Raouf and Jean-Pierre Laffargue, "A Theory of Dynamics and Inequalities Under Epidemics," 2007. CORE Discussion Paper 2007/37.

Brown, T., N. C. Grassly, G. Garnett, and K. A. Stanecki, "Improving Projections at the Country Level: The UNAIDS Estimation and Projection Package 2005," Sexually Transmitted Infections, 2006, 82 (3), 34-40.

Cohen, Daniel and Marcelo Soto, "Growth and Human Capital: Good Data, Good Results," Journal of Economic Growth, 2007, 12, 51-76.

Conley, Dalton, McCord Gordon C., and Jeffrey Sachs, "Africa's Lagging Demographic Transition: Evidence from Exogenous Impacts of Malaria Ecology and Agricultural Technology," 2006.

de la Fuente, Angel and Rafael Doménech, "Human Capital in Growth Regressions: How Much Difference Does Data Quality Make? An Update and Further Results," 2002. CEPR Discussion Papers, $n^{\circ} 3857$.

Eriksson, Mikael and Peter Wallensteen, "Armed Conflict, 1989-2003," Journal of Peace Research, 2004, 41 (5), $625-636$.

Galor, Oded and Omer Moav, "Natural Selection and the Origin of Economic Growth," The Quarterly Journal of Economics, 2002, 117 (4), 1133-1191.

Ghys, P. D., T. Brown, N. C. Grassly, G. Garnett, K. A. Stanecki, and J. Stover, "The UNAIDS Estimation and Projection Package: A Software Package to Estimate and Project National HIV Epidemics," Sexually Transmitted Infections, 2004, 80 (S1), 5-9.

Grassly, N. C., M. Morgan, N. Walker, G. Garnett, K. A. Stanecki, J. Stover, T. Brown, and P. D. Ghys, "Uncertainty in Estimates of HIV/AIDS: The estimation And Application of Plausibility Bounds," Sexually Transmitted Infections, 2004, 80 (S1), 31-38.

Gray, Ronald H., Maria J. Wawer, Maria J. Serwadda, Nelson Sewankambo, Chuanjun Li, Frederick Wabwire-Mangen, Lynn Paxton, Noah Kiwanuka, Godfrey Kigozi, Joseph Konde-Lule, Thomas C. Quinn, Charlotte A. Gaydos, and Denise McNairn, "Population-based Study of Fertility in Women With HIV-1 Infection in Uganda," The Lancet, 1998, 351 (9096), 98-103.

Hansen, L., "Large Sample Properties of Generalizes Method of Moments Estimators," Econometrica, 1982, 50 (3), 1029-1054.

Hazan, Moshe and Hosny Zoabi, "Does longevity cause growth? A theoretical critique," Journal of Economic Growth, 2006, 11, 363-376.

Herlihy, David, The Black Death and the transformation of the West, Cambridge: Harvard University Press, 1997.

Heston, Alan, Robert Summers, and Bettina Aten, Penn World Table Version 6.2, Center for International Comparisons of Production, Income and Prices at the University of Pennsylvania, 2006.

Kalemli-Ozcan, Sebnem, "Does the mortality decline promote economic growth?," Journal of Economic Growth, 2002, 7, 411-439. 
_ , "A Stochastic Model of Mortality, Fertility, and Human Capital Investment," Journal of Development Economics, 2003, 70, 103-118.

_, "AIDS, "Reversal" of the Demographic Transition and Economic Development: Evidence from Africa," 2008. NBER Working Paper, n¹2181.

_ , "The Uncertain Lifetime and the Timing of Human Capital Investment," Journal of Population Economics, 2008, forthcoming.

Kremer, Michael and Daniel Chen, "Income distribution dynamics with endogenous fertility," Journal of Economic Growth, 2002, 7, 227-258.

Krueger, Alan B. and Mikael Lindahl, "Education for Growth: Why and for Whom?," Journal of Economic Literature, 2001, 39 (4), 1101-1136.

Lewis, James J.C., Carine Ronsmans, Carine Ezeh, and Simon Gregson, "The Population Impact of HIV on Fertility in Sub-Saharan Africa," AIDS, 2004, 18 (2), 35-43.

Lyerla, R., E. Gouws, J. M. Garcia-Calleja, and E. Zaniewski, "The 2005 Workbook: An Improved Tool For Estimating HIV Prevalence in Countries With Low Level and Concentrated Epidemics," Sexually Transmitted Infections, 2006, 82 (S3), 41-44.

Mankiw, N. Gregory, Macroeconomics, 5th Edition, Worth Publishers, 2005.

Murray, Michael P., "Avoiding Invalid Instruments and Coping with Weak Instruments," Journal of Economic Perspectives, 2006, 20 (4), 111-132.

Oster, Emily, "Sexually Transmitted Infections, Sexual Behavior, and the HIV/AIDS Epidemic," Quarterly Journal of Economics, 2005, pp. 467-514.

_ , "Routes of Infection: Exports and HIV Incidence in Sub-Saharan Africa," 2007. mimeo.

Pregibon, Daryl, "Goodness of Link Tests for Generalized Linear Models," Applied Statistics, 1980, 29 (1), 15-24.

Ramsey, James B., "Tests for Specification Errors in Classical Linear Least-Squares Regression Analysis," Journal of the Royal Statistical Society, 1969, 31 (2), 350-371.

Roodman, David, "The Anarchy of Numbers: Aid, Development, and Cross-country Empirics," 2004. Center for Global Development Working Paper, n³2.

_ , "A Short Note on the Theme of Too Many Instruments," 2007. Center for Global Development, $\mathrm{n}^{\circ} 125$.

Soares, Rodrigo, "Mortality Reductions, Educational Attainment, and Fertility Choice," American Economic Review, 2005, 95 (3), 580-601.

Stover, John, "Projecting the Demographic Consequences of Adult HIV Prevalence Trends: the Spectrum Projection Package," Sexually Transmitted Infections, 2004, 80 (S1), 14-18.

Timæus, Ian M. and Momodou Jasseh, "Adult Mortality in Sub-Saharan Africa: Evidence from Demographic and Health Surveys," Demography, 2004, 41 (4), 757-772. 
UNAIDS, 2004 Report on the global AIDS epidemics, Joint United Nations Programme on $\mathrm{HIV} / \mathrm{AIDS}, 2004$.

United Nations Population Division, World Population Prospects: the 2006 Revision, New York: United Nations Publications, 2007.

Walker, N., N. C. Grassly, G. P. Garnett, K. A. Stanecki, and P. D. Ghys, "Estimating the Global Burden of HIV/AIDS: What Do We Really Know About the HIV Pandemic?," Lancet, 2004, 963 (9427), 2180-2185.

Windmeijer, Frank, "A Finite Sample Correction For the Variance of Linear Efficient Two-step GMM Estimators," Journal of Econometrics, 2005, 126 (1), 25-51.

World Bank, Confronting AIDS: Public Priorities in a Global Epidemic, New York: Oxford University Press, 1997.

_, World Development Indicators 2007. Online Database.

Young, Alwyn, "The Gift of the Dying: The Tragedy of AIDS and the Welfare of Future African Generations," Quarterly Journal of Economics, 2005, pp. 423-466.

_ , "In Sorrow to Bring Forth Children: Fertility amidst the Plague of HIV," Journal of Economic Growth, 2007, 12 (4), 283-327.

Zhang, Jie and Junsen Zhang, "The Effect of Life Expectancy on Fertility, Saving, Schooling and Economic Growth: Theory and Evidence," Scandinavian Journal of Economics, 2005, 107 (1), 45-66. 


\section{Appendix 1}

In table 6 the empirical model is re-estimated with ten year panel data from 1960 to 2004. Values for the fertility and conflict variables correspond to five year averages over the periods 1960-1964, 1970-1974, 1980-1984, 1990-1994, 2000-2004. Values for the other variables correspond to the years 1960, 1970, 1980, 1990, 2000. Compared to table 3, results are qualitatively unchanged.

\begin{tabular}{|c|c|c|c|c|}
\hline \multirow{2}{*}{ Determinants } & \multicolumn{4}{|c|}{ Fertility } \\
\hline & $(1)^{\prime}$ & $(2)^{\prime}$ & $(3)^{\prime}$ & $(4)^{\prime}$ \\
\hline Child mortality $_{l n}$ & $\begin{array}{c}1.56^{a} \\
(0.42)\end{array}$ & $\begin{array}{c}1.53^{a} \\
(0.40)\end{array}$ & $\begin{array}{l}1.58^{a} \\
(0.44)\end{array}$ & $\begin{array}{c}1.10 \\
(2.55)\end{array}$ \\
\hline Adult mortality ${ }_{l n}$ & $\begin{array}{l}-1.02^{a} \\
(0.34)\end{array}$ & & & $\begin{array}{l}-1.33^{b} \\
(0.62)\end{array}$ \\
\hline Male adult mortality ${ }_{l n}$ & & $\begin{array}{l}-1.05^{a} \\
(0.35)\end{array}$ & & \\
\hline Female adult mortality ${ }_{l n}$ & & & $\begin{array}{c}-0.96^{a} \\
(0.33)\end{array}$ & \\
\hline Real GDP per capita $l n$ & $\begin{array}{l}-0.55^{a} \\
(0.18)\end{array}$ & $\begin{array}{c}-0.54^{a} \\
(0.18)\end{array}$ & $\begin{array}{c}-0.56^{a} \\
(0.19)\end{array}$ & $\begin{array}{l}-0.60 \\
(2.02)\end{array}$ \\
\hline Average years of schooling & $\begin{array}{l}-0.04 \\
(0.05)\end{array}$ & $\begin{array}{l}-0.04 \\
(0.05)\end{array}$ & $\begin{array}{l}-0.04 \\
(0.06)\end{array}$ & $\begin{array}{l}-0.15 \\
(0.10)\end{array}$ \\
\hline Occurrence of a territorial conflict & $\begin{array}{c}0.15 \\
(0.28)\end{array}$ & $\begin{array}{c}0.14 \\
(0.27)\end{array}$ & $\begin{array}{c}0.15 \\
(0.29)\end{array}$ & $\begin{array}{l}-0.24 \\
(1.23)\end{array}$ \\
\hline Constant & $\begin{array}{l}7.70^{b} \\
(3.13)\end{array}$ & $\begin{array}{l}8.14^{b} \\
(3.20)\end{array}$ & $\begin{array}{l}7.22^{b} \\
(3.08)\end{array}$ & $\begin{array}{c}12.73 \\
(24.35)\end{array}$ \\
\hline Observations & 159 & 159 & 159 & 159 \\
\hline Countries & 37 & 37 & 37 & 37 \\
\hline Instruments & 35 & 35 & 35 & 15 \\
\hline Arellano-Bond test $\mathrm{AR}(1) \mathrm{p}$-value & 0.07 & 0.06 & 0.08 & 0.83 \\
\hline Arellano-Bond test $\mathrm{AR}(2) \mathrm{p}$-value & 0.28 & 0.33 & 0.24 & 0.14 \\
\hline Hansen overidentification test p-value & 0.34 & 0.33 & 0.35 & 0.29 \\
\hline Difference-in-Hansen test level GMM p-value & 0.31 & 0.33 & 0.36 & 0.29 \\
\hline Difference-in-Hansen test IV p-value & 0.45 & 0.41 & 0.50 & 0.48 \\
\hline
\end{tabular}

Notes: a, b, c denotes respectively significance at the 1, 5 and $10 \%$ level. ${ }_{n}$ : variable in logarithms.

Standard errors are in parentheses. All GMM standard errors are heteroscedasticity- and autocorrelation-robust and include the Windmeijer (2005) finite-sample correction. In regression (4) instruments are collapsed. Unreported time dummies are included.

Table 6: Child mortality, adult mortality and fertility in Africa (1960-2004) 


\section{Appendix 2}

Variables are frequently measured with errors and therefore their reliability needs to be carefully assessed. For instance, if $X_{1}$ is a noisy measure of $Z$, with $X_{1}=Z+\epsilon$, its reliability $\lambda_{X_{1}}$ can be defined as the signal-to-total variance ratio: $\lambda=\frac{\operatorname{Var}(Z)}{\operatorname{Var}\left(X_{1}\right)}=\frac{\operatorname{Var}(Z)}{\operatorname{Var}(Z+\epsilon)}$. However, the value of $Z$ is frequently unknown. Reliability of $X$ can nevertheless be approximated if a second noisy measure of $Z$, e.g. $X_{2}$, is available. If the errors of these two variables are uncorrelated with each other and with the true value, their covariance provides an approximation of the variance of the true value. In that case $\lambda_{X_{1}} \simeq \frac{\operatorname{Cov}\left(X_{1}, X_{2}\right)}{\operatorname{Var}\left(X_{1}\right)}$. Note that if the errors in $X_{1}$ and $X_{2}$ are positively correlated, the estimated reliability ratios will be biased upwards and may exceed the value of one. Hence, they should cautiously be interpreted as providing an upper bound on the reliability of the data series.

The formula used to calculate the reliability ratios coincides with that used to calculate the slope coefficient of a simple regression model. Hence, OLS regressions are run with each variable of interest alternatively acting as dependent or independent variable. Following Krueger and Lindahl (2001) and de la Fuente and Doménech (2002), all regressions include time dummies and are not only run in level but also in first-differences in order to assess whether changes in the data still convey some signal. Alternative measures of education, GDP per capita, adult mortality rates and HIV prevalence respectively come from Cohen and Soto (2007), Heston et al. (2006), Timæus and Jasseh (2004) ${ }^{25}$ and Oster (2007). No second measure of child mortality rates was found. Their estimates are associated with about a $+/-15 \%$ range of uncertainty and are considered more reliable than the estimates of child mortality as the indirect demographic techniques used to estimate the former are more robust and less sensitive to assumptions about underlying mortality patterns than are the techniques used to estimate the latter (Ahmad et al., 2000).

The estimated reliability ratios are reported in table 7 . The data series on which the empirical findings of this paper are based appear fairly reliable. Focusing on adult mortality rates and HIV prevalence, the reliability ratios suggest that the informational content of these variables is very high, even when expressed in percent changes (growth rates). In the latter case it is not surprising as for most of the countries included in the sample, trends fitted from antenatal data have been recalibrated to adjust urban and rural HIV levels to those measured in population-based surveys, in order to reflect more accurately the national situation.

\footnotetext{
${ }^{25}$ As outlined by Blacker (2004), their estimates of adult mortality, based on sibling histories collected in Demographic and Health Surveys, appear unreasonable for Ethiopia and Nigeria. These two countries have been therefore omitted from the sample.
} 


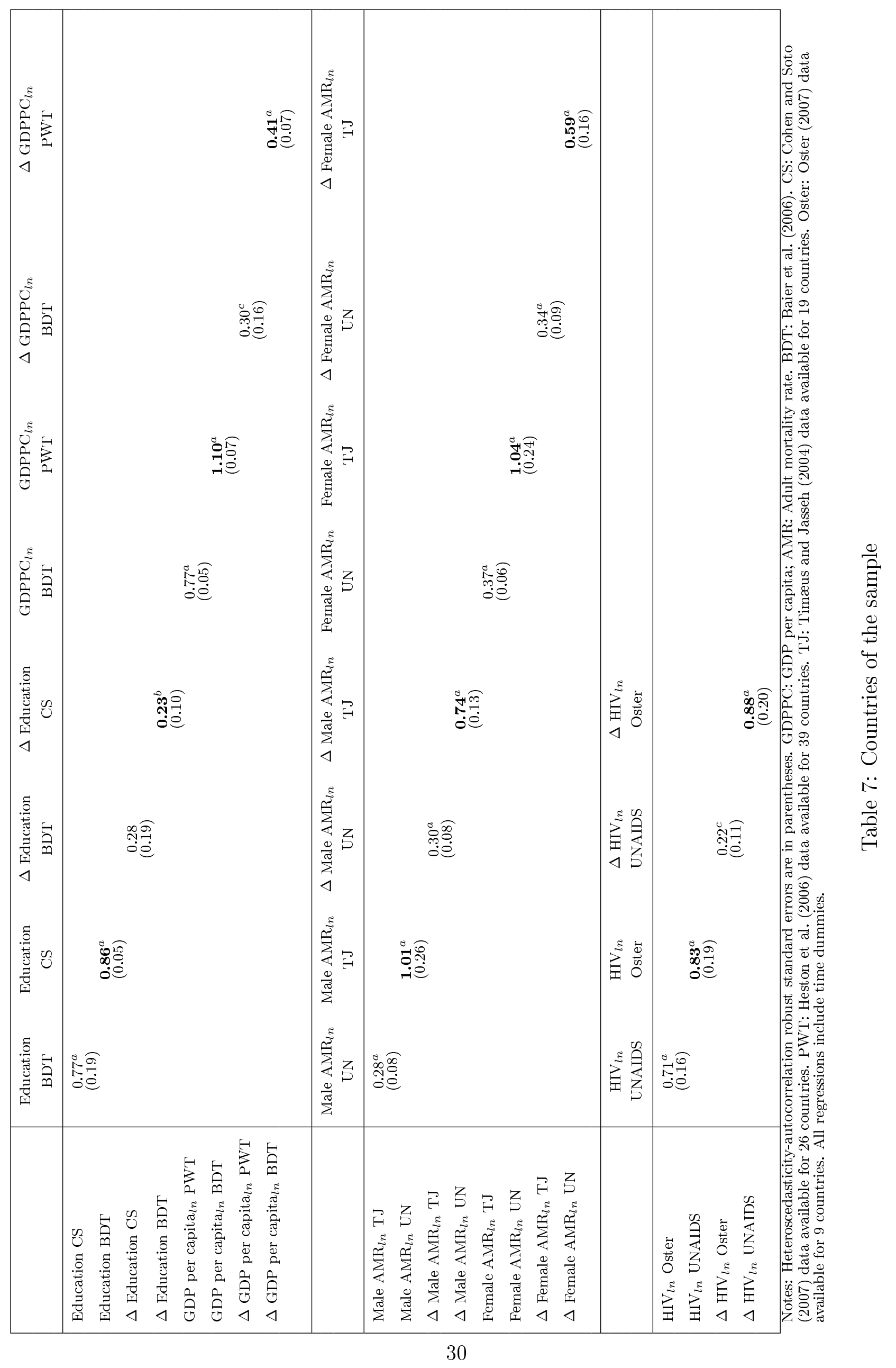


Département des Sciences Économiques de l'Université catholique de Louvain

Institut de Recherches Économiques et Sociales

Place Montesquieu, 3

1348 Louvain-la-Neuve, Belgique 